\title{
Group Model Building: A Systematic Review of the Literature
}

\author{
Ali Haji Gholam Saryazdi \\ $\mathrm{PhD}$ in Information Technology Management (Intelligent Business), Tarbiat Modares \\ University, Tehran, Iran, (Corresponding Author),A.hajigholam@modares.ac.ir
}

\section{Ali Rajabzadeh Ghatari}

Professor, Faculty of Management and Economics (Department of Information Technology

Management), Tarbiat Modares University, Tehran, Iran, Alirajabzadeh@modares.ac.ir

\section{Ali Naghi Mashayekhi}

Professor of Management and Economics, Sharif University of Technology, Tehran, Iran, Mashayekhi@sharif.edu

\section{Alireza Hassanzadeh}

Associate Professor, Faculty of Management and Economics (Department of Information Technology Management), Tarbiat Modares University, Tehran, Iran,

Ar hassanzadeh@modares.ac.ir

\begin{abstract}
System dynamics is a method for the model building of complex socioeconomic phenomena. One of the important sources of information is the mental model. Group model building was devised to extract mental models. Since this modeling method was proposed for the first time, it has been applied by many researchers, and a lot of research has been conducted about how to practice it, its instructions, and their evaluation. This paper seeks to make a comprehensive review of the literature associated with this method. To achieve this goal, a systematic review is made of 156 articles published until 2017 on group model building, the findings of those studies are summed up, and their orientation pattern is determined through identifying the focuses of attention of researchers. Finally, the existing research gaps are identified and explained, and some suggestions are given for future research in the field of group model building.

Keywords: System Dynamics Approach, Mental Model, Group Model Building, Systematic Review of the Literature.

\section{Introduction}

System dynamics is a method for understanding the behavior of complex systems over time. In this regard, model building of complex socioeconomic phenomena was introduced by Forrester at MIT in the 1950s (Château et al., 2012). The approach is rooted in the control theory and nonlinear dynamics (Sterman, 2000) and is a combination of the systems theory, cybernetics, servomechanism, information theory, decision theory, and computer simulation (Chen et al., 2014). At first, this approach aimed to help managers understand industrial processes but,
\end{abstract}


nowadays, it involves a range of social sciences, economic, cultural and natural disciplines, and areas from decision-making in business to medical and biological model building, as well as from environmental systems to public policy-making (Antunes et al., 2006). Since the approach was designed, different tools, software programs, processes, and information resources have provided for model building system dynamics (Ackermann and Vennix, 1996). One of the important sources of information is the stakeholder mental model that has been emphasized since the very beginning of this approach so as for Forrester to consider it important to involve customers in system dynamics model building (Forrester, 1961). Doyle and Ford (1997) state that "A mental model of a system dynamics is a relatively enduring and accessible, but limited, internal conceptual representation of an external system (historical, existing or projected) whose structure is analogous to the perceived structure of that system"(Doyle and Ford, 1997).

In order to extract mental models, various methods such as using individual interviews (individual model building), participatory model building, and group model building have been created.

Group model building is a participatory method to extract knowledge from experts of the studied problem through official activities and facilitated discussions, which has applications from problem definition to simulation in system dynamics (Hernantes et al., 2013). In other words, in group model building sessions, experts provide their individual perspectives on the problem, its structure, the resulting dynamic model, as well as the results and solutions. These views are improved by knowledge sharing of people, discussions, and group analysis. In case of a consensus on the final model, the group reaches an effective solution to resolve the problem, and the commitment of people to execute their tasks is increased.

Group model building is a powerful tool for extracting and eliciting stakeholder mental models and combining them in a system dynamics model. On the other hand, the model building of system dynamics helps participants in group model building to define, clarify, and organize their ideas into a shared view (Château et al., 2012).

Winz and Gary (2007) state that stakeholders' participation in system dynamics is not a new phenomenon. However, involvement of stakeholders in all the steps has grown within the last 20 years with the aim of improving learning and supporting the implementation and use of the model in the form of group model building (Vennix et al., 1997).

Since its emergence, the group model building method has been rapidly expanding (Antunes $e t$ al., 2006; Olabisi, 2013) such that it is practically applied in many researches (Antunes et al., 2006; Elias, 2008a). Also, many studies have been conducted about the method, its modeling process, instructions, and evaluation (Groesser, 2006). This can be of benefit to sum up the findings and the major tenets of these separately done studies.

The first empirical study was conducted in 1988 by reviewing the corresponding pieces of research that had been done during the past 13 years (Scott, Cavana and Cameron, 2016). Then, Rouwette, Vennix, and Mullekom (1999) reviewed studies on the evaluation of group model building through a systematic and empirical research. They reviewed articles related to group model building and other techniques such as the reference group approach, strategic forums, participatory policy model building, model building as learning, soft systems methodology, and cognitive maps. These items were presented in the System Dynamics Conference from 1981 through 1997, the Journal of System dynamics review from 1985 through 1997, and other publications. In their study, a total of 75 papers involving 81 model building cases were examined in five categories including background characteristics, client organization, problem to be modeled, type of intervention, and evaluation of modeling impacts (Rouwette, Vennix, and Mullekom, 1999). They also extended their study in 2002 and reviewed the group model building literature by examining 107 articles during 1987-2000. Based on their review, only three articles 
were published before 1970, four articles during the 1970s, 16 during the 1980s, and 62 papers were published in the 1990s. In their papers, they reviewed aspects such as the source of data (e.g. modeling team, participants), the type of data collected, how the data were collected (e.g. interviews, questionnaires, (in)formal observations), when data were collected (i.e. pre, post, during intervention), and how they were found (Rouwette, Vennix, and Mullekom, 2002).

By reviewing the genealogy of group model building, Zagonel (2002) found that it has stemmed from two schools of thought. The first school is the system dynamics approach which is rooted in the thread of policies. The second school or mode of thinking is the thread of decisions which forms the decision conferencing framework. By purposeful sampling of the literature, they identified five categories including classic system dynamics, direct system dynamics modeling with clients, decision conferencing, system dynamics modeling used in decision conferences, and group model building. It is suggested that, with those two different routes in the genealogy of group model building, there are two approaches to consider. In the first approach, model building is as a representation of reality or the micro world which is based on the thread of decisions. In the second approach, model building is as a tool for discussion or negotiation in a social order or on a boundary object that is based on the thread of policies. Then, Zagonel (2004) did some review of the group model building literature to examine the tension between model as a micro world (representing reality) and model as a boundary object (a tool for discussion in a social order).

Also, Scott, Cavana and Cameron (2016) have sought to extract published quantitative evidence on group model building by reviewing 100 articles, taking into account three questions including 'what does it achieve?', 'when should it be applied?', and 'how should it be applied or improved?'. They generally argue that, as the evidence indicates, group model building is improving and helps to improve communication and consensus among the participants in group decision-making processes. They also suggest that future research related to group model building should represent three shifts: from single cases to multiple cases, from controlled settings to applied settings, and toward augmenting surveys with more objective measures (Scott, Cavana and Cameron, 2016).

Considering the necessity of reviewing previous studies on group model building, both in aspects that have not been reviewed yet and in greater time periods, this paper aims at a comprehensive review of the literature related to group model building. In this study, through the systematic review of 156 articles published until 2017 on group model building, we have summed up the pieces of research and determined their orientation patterns through identifying the focuses of attention of the researchers.

In the following, the research method used in this paper is explained. Then, based on the analysis of the studies on group model building, we will provide findings of the literature review.

\section{Methodology}

In this paper, using a library method and through a systematic review of the literature, we review the studies on group model building.

Compared with traditional or narrative literature review methods, the method of Systematic Review of the Literature deals with literature review in one specialized field with a more precise and well-defined approach (Ryan, 2010). In this method, based on a specific issue or question, the conducted studies are reviewed and then, beside assessing and evaluating their relevance, evidence is extracted and summarized in relation to that issue or question. (Khan et al., 2003; Ryan, 2010). This approach causes a decline of biases and leads to acquisition of accurate information of the phenomenon in consistence with the literature, identification of factors 
affecting the phenomenon, and creation of a model of the phenomenon using the literature (Zurynski, 2014)

In the present study, the studied subject is group model building that is mentioned in the full texts of all the articles in the first two rounds of the research conference on system dynamics in 1976 and 1981 as well as 33 rounds of system dynamics conference from 1983 to 2015. Also, articles of scientific databases of Elsevier, Wiley Online Library published until 2017 have mentioned the terms "Group Model Building" and "GMB" in their titles, abstracts or keywords. It should be noted that this article only focuses on group model building and does not involve studies related to other similar methods such as reference group approach, strategic forum, participatory policy model building, model building as learning, soft systems methodology, and map cognitive. It also focuses on journals and conference papers while other documents are not investigated. The survey was conducted until 2017, and only English language documents were studied. Accordingly, a number of 195 primary articles were identified some of which, in more in-depth studies, were eliminated due to lack of complete focus on the subject. Ultimately, a total of 156 fully related papers were analyzed.

According to Scott, Cavana and Cameron (2016), article search results may be biased due to the following three reasons:

1) It is possible that studies on group model building exist in other sources that have not been studied.

2) It is possible that some articles have been removed due to human error.

3) It is possible that all the research and studies in the field of group model building are not published for various reasons such as doubt, commercial sensitivity, and avoidance of releasing unsuccessful cases.

\section{The analysis of previous research}

After collecting the relevant articles, each article was reviewed and summarized within 12 areas. The following diagram shows the number of articles whose main focus is on group model building. As it can be seen, there exist a total of 156 articles. The first article dates back to 1988, and there are about 32 papers until 2000. The first article published in a scholarly journal belongs to 1996. 


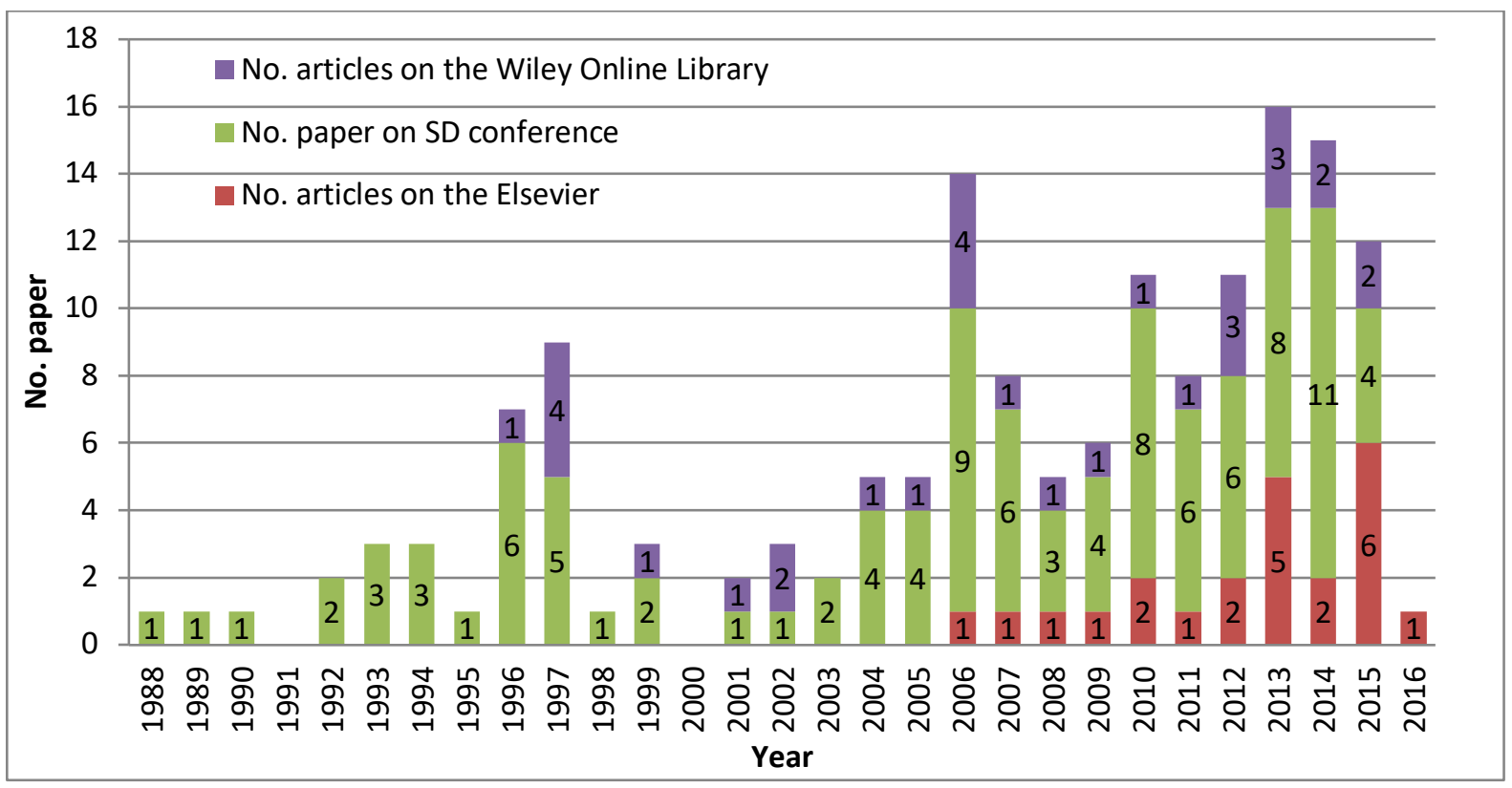

Figure 1. Diagram of the number of articles related to group model building

In the following, the results of a full investigation of 156 articles related to group model building are provided within the context of the itemized areas: Definitions of group model building, The type of suitable problems, Outputs of group model building, Group model building processes, Different roles in group model building, Advantages and disadvantages of group model building , Findings in terms of the research methodology, Findings in terms of the modeling type, Findings in terms of the application or modeling area, Findings in terms of the number of participants in group sessions, Findings in terms of the geographical regions, Findings in terms of the relevant journals.

\section{Definitions of group model building}

In this section, we provide definitions of group model building according to various specialists. Ackermann (1995) introduces participative business modeling (PBM) as "a synergistic blend of system dynamics and group knowledge elicitation techniques". Vennix (1996) and Vugteveen $e t$ al. (2015) suggest that group model building (GMB) is defined as "a method involving facilitators (usually a modeling team) and a group of stakeholders that co-build a model to solve problems within a complex system". Some researchers have defined group model building from the perspective of participatory model building. For example, Renger, Kolfschoten and de Vreede (2008) consider participatory model building as a term to describe model building approaches that deal with creation of a model with the participation of end users, stakeholders, experts and analysts. Anderson et al. (2007) argue that Participatory Model Building (PMB) refers to resource management forms rooted in integration of stakeholder input to conduct the process and results. In participatory model, stakeholders have a large control on model building, intervention, the proposed policy solutions, and testing and applying them (Butler and Adamowski, 2015). In this type of model building, the level of participation is dependent on different selected methods. Group model building (GMB) is a subset of Participatory Model Building (PMB) where stakeholders are engaged in developing, testing and applying models as a group. Stakeholder, in a broad sense, means anyone who can affect or be affected by a system under study (Garrod et al., 2013). 
Elias (2008b) views group model building as "a process in which team members exchange the perceptions of a problem and explore such questions as What exactly is the problem we face? How did the problematic situation originate? What might be its underlying causes? How can the problem be effectively tackled?".

Group model building has repeatedly been used to extract knowledge from a group of experts familiar with the subject matter (Vennix et al., 1990; Vennix, 1999). Rich individualistic knowledge is used in group model building (Goh et al., 2012). In other words, in group model building, the individual-level dimensions including the reaction, insight into the problem and other assumptions, commitment and behavior, and group-level dimensions including communication, shared language and consensus are taken into consideration (Brömmelstroet, 2013).

Hovelynck et al. (2010) suggest that group model building is one of the approaches to the integration of knowledge and is based on a participatory method that, in turn, depends on a system dynamics approach. It is rooted in simulation modeling by face-to-face sessions with clients (Hovelynck et al., 2014)

Finally, it can be said that group model building is a specific case of problem structuring method (PSM) and, as Anderson et al. (2007) have described it, "a bundle of techniques used to construct system dynamics models working directly with client groups on key strategic decisions". The method is specifically designed for the development of SD models (Esensoy and Carter, 2015).

\section{Type of problems}

According to the literature, group model building is more concerned with ill-defined strategic issues, messy problems, wicked problems and unstructured problems (Vennix et al., 1988; Vennix, 1999; Carter et al., 2013; Halbe et al., 2015; Vugteveen et al., 2015). Messy and wicked problems are those with features such as high complexity and multi-causality, difficulty of defining, analyzing and solving (Rettel and Webber, 1973; Groesser, 2006; Smagt, 2006; Wagner et al., 2010; Butler and Adamowski, 2015). Problem complexity consists of technical complexity (e.g. high number of variables and nonlinear relationships between them) and organizational complexity (e.g. existence of individuals with opposed opinions and preferences). Its difficulty is due to imperfect information (Qian and Gonzalez, 2006). The other factors in this case are unknown feedback loops, qualitative data, heterogeneity of stakeholders which is also due to the presence of various stakeholders with opposed views and divergent opinions in defining the problem and solutions, different interests and lack of trust, involvement of too many institutions, overlapping jurisdictions and spheres of influence, multiple users with different records, expressions and knowledge, as well as different ways to intervene in problem (Roos, 1997; Groesser, 2006; PahlWostl, 2007; Château et al., 2012; Hernantes et al., 2013; Pagani and Otto, 2013; Halbe et al., 2015; Vugteveen et al., 2015, Flynn, 2015). Apart from the complexity of these issues, there are adverse effects of managers' measures that lead to delays (Sterman, 2000; Goh et al., 2010 a, b), causing border challenges and distance of causes from effects either in time dimension or in place dimension (Pahl-Wostl, 2007). In other words, dynamic, nonlinear messy problems with multiple and inconsistent boundaries are not limited to political or geographical areas of the problem; but rather, they include different laws and regulations, awareness, language and culture (Ford and Sterman, 1997; Hernantes et al., 2013). These problems are usually transdisciplinary (Ford and Sterman, 1997) and require the use of various sciences, combining transdisciplinary sciences and intersectoral actions (Beall and Ford, 2007). In this regard, group model building involves different stakeholders, including scientific experts in different fields, policy-making experts, program managers, front-line workers, communities, and end users (clients) to draw the model (Munar et al., 2015). 
Antunes et al. (2006) argue that, when our problems are in a post-normal science paradigm, in other words, when the data are highly uncertain, when the values and quantities are controversial and high risks and urgent decisions are needed, and when the studied issues have a dynamic complexity and require an integrated perspective (Chen et al., 2014), ordinary scientific approaches do not work; in such cases, policy debates need to be held with the participation and involvement of all walks of life (Funtowicz and Ravetz, 1994). So, in such issues, group model building is needed (Antunes et al., 2006). This is because an important feature of this method is that the fact is separated from values, the main focus is on descriptive and diagnostic perspectives (Elias, 2008 b), and the goal is to create consensus (Vennix, 1996).

McCardle-Keurentjes, Rouwette and Vennix (2008) state that group model building is formidable in discovering hidden profiles in strategic decision-making processes. Hidden profile exist when 1) the information related to a decision is distributed among the members of the decision-making group and each member has a unique part of this information, and 2) it is required to integrate these pieces of information so that the alternative of a superior decision can be chosen (McCardleKeurentjes, Rouwette and Vennix, 2008).

In response to the question 'What time should group model building be used?' Scott, Cavana and Cameron (2016) express that the method is useful in various fields such as policy-making, developing and implementing strategies, and within-organizational and inter-organizational agreements. They argue that, although group model building does not work in certain different fields, a great bulk of literature has remained silent on this point. However, the literature indicates that group model building is effective in complex pluralist situations (Scott, Cavana and Cameron, 2016). When there is a need for recognizing the complexities of a system, integration of stakeholders' knowledge and desirability of communication and learning among stakeholders may give potentials to the group model building (Vugteveen et al., 2015)

Finally, it can be said that, in this model building method, development of a system dynamics model takes place through knowledge extraction from one or more experts. The extraction of knowledge from experts is because this knowledge about the system does not exist in the literature (Vennix et al., 1988).

\section{Model building outputs}

One of the important elements in group model building is to determine the modeling output (Andersen and Richardson, 1994). Regarding the output of group model building sessions, we have created three categories in this paper based on the review of different papers. The first category includes:

1) System dynamics simulation models/ stock and flow diagrams (SFD)/ quantitative models (Andersen and Richardson, 1994; 1997; Ackermann, 1995; Zagonel, 2004; Groesser, 2006).

2) Conceptual models/ casual loop diagrams (CLD)/ qualitative models (Ackermann, 1995; Checkland and Scholes, 1999; Rouwette et al., 2004; Zagonel, 2004; Groesser, 2006). In group model building, it is mostly qualitative (conceptual) model building that takes place (Vennix, 1994; Rouwette, Vennix, and Mullekom, 1999).

3) Scripts and guidelines for group model building and management of sessions (Andersen and Richardson, 1997; 2010; Luna-Reyes et al., 2005; 2006; Anderson et al., 2007; 2009a; 2009b; 2013; Calhoun et al., 2010; Ackermann et al., 2010; 2011; Homand et al., 2011; 2012; Homand and Rouwette, 2013; 2014; 2015).

Of the determinants of the model building approach and output, one can refer to the availability of quantitative data, the purpose of the study, and the research approach (Coyle, 1999). If 
quantitative data are not available, or the purpose of the study is to extract variables and models from different divergent perspectives, or the research is exploratory, a qualitative approach is more appropriate (Goh et al., 2012). In other words, in subjects where data are limited and the majority are qualitative, engaging stakeholders directly is appropriate, and both deductive and inductive logic can be used to detect mental models qualitatively (Richards et al., 2013; Pagani and Otto, 2013).

The second category regarding the output of group model building sessions includes:

1) Model as a micro world (Zagonel, 2002; 2004) or as a representative object (Bayer et al., 2010) or a virtual world (Sterman, 2000) which is a presentation of the reality of a foreign policy-making environment. In other words, micro world models are used as the actual representation of a decision-making position for testing the results of policy choices (Zagonel, 2002; 2004; Eden and Ackermann, 2006; Martinez-Moyano et al., 2007; Bayer et al., 2010; Timothy et al., 2011; Esensoy and Carter, 2015; Scott, Cavana and Cameron, 2016).

2) Model as a boundary object, a transitional object or a socially constructed artifact which is a tool for discussion, confidence building, shared understanding, and agreement (Zagonel, 2002; 2004; Eden and Ackermann, 2006; Martinez-Moyano et al., 2007; Bayer et al., 2010; Timothy et al., 2011; Black and Anderson, 2012; Black, 2013; Esensoy and Carter, 2015; Com, 2015; Scott, Cavana and Cameron, 2014; 2016).

It is important to note that, in some cases, the distinction between the two (namely micro world and boundary object) is not clear (Zagonel, 2002), and, in some other cases, the output is a combination of the two (Scott, Cavana and Cameron, 2014; 2016). In addition, the model, whether as a boundary object or as a micro world, can be an epistemic or technical object. Epistemic objects help to create new knowledge and are fluid while technical objects are static and serve as a means of making the existing knowledge available (Bayer et al., 2010).

Finally, it should be said that there is a difference between a model building process and its output. In a group model building process, attempt is always made to discover mental models, structures and data and to clarify them, while the output of model building may be the learning that results from the model building process or a problem-describing model (Laurenti et al., 2014; Vugteveen et al., 2015). In other words, given the framework of Location-Form Continuum proposed by Kim (2007), group model building is located between the output continuum (the same model) and the process (Kim, 2007). It can also be said that engaging users is important for knowledge acquisition and diffusion (Vennix et al., 1988).

The third category regarding the output of group model building sessions based on the objective includes:

1) Solution to the problem (practical approach): It is mainly group model building by involving managers to solve a specific problem (Luna-Reyes, 2004; Zagonel, 2004). For example, Siemer and Otto (2005) used group model building to make decisions in the field of wildlife management (Siemer and Otto, 2005).

2) New theory (academic approach): In some studies, group model building is used for theory building (Zagonel, 2004; Luna-Reyes et al., 2006; 2013; Kuhlberg, 2015), such as dynamic social theory about the complexity of inter-organizational information integration (Luna-Reyes, 2004). In their article, Luna-Reyes et al. (2005) used group model building for theorizing in IT innovation (Luna-Reyes et al., 2005). Luna-Reyes et al. (2013) developed a theory of the impacts of governance principles on the adoption of a large-scale inter-organizational system to increase supply chain transparency (I-Choose information system) (Luna-Reyes et al., 2013). 


\section{Model building process}

So far, many experts have done a lot of research in the field of group model building. Designing a model building process is usually done through scripts. In this regard, Anderson and Richardson $(1994,1997)$ developed a series of small-group semi-structured processes on the basis of before-workshop scripts. These scripts contain tasks related to individuals, small groups, and whole groups that attend workshops. Also Ackermann et al. (2011) have provided a script map which is a framework for a combination of successive activities, products, and deliverables in a formal network to enable facilitators to plan and conduct group model building workshops. In this script, two methods of system dynamics and journey taking are combined. Different authors have also developed different procedures and approaches for participatory model building. As an example, Ackermann (2001) provides the Renga approach which involves individual, group, and general interviews.

A group model building process has three general phases (Anderson, Richardson and Vennix, 1997; Winz and Gary, 2007) in each of which different activities are carried out. Of course, these general phases and their corresponding steps may be not done depending on each case and according to circumstance; rather, they may be realized in other ways. Another important point is that the phases and steps are repeated and reciprocating (Groesser, 2006; Butler and Adamowski, 2015).

The phase before group model building workshops (i.e. planning phase):

In this phase, firstly, a model building team including a group of system dynamics researchers and a group of client representatives, who undertake the management of a group model building project in various roles, is formed. The roles players include facilitators, moderators, modellers, process coaches and gatekeepers (Esensoy and Carter, 2015). Then, the problem is defined or its overall subject is reviewed and agreed on by the client and the modeling team (Ackermann, 1995; Zagonel et al., 1997). Then, the modeling team starts its initial studies including the literature review and client documentation (Halbe and Adamowski, 2011). Since recognizing the problem participants and audience is a vital step (Richardson et al., 1989) and it is needed to engage them deeply (De Gooyert et al., 2013), context and content analysis and problem's stakeholder analysis based on the literature, brainstorming with or without the support of the snowball method and institutional analysis (Elias, Cavana and Jackson, 2004; Elias, 2006; Antunes et al., 2006; Groesser, 2006; Elias, 2008b; Cavana and Adams, 2010; Halbe and Adamowski, 2011; Inam et al., 2015), the use of various means of mass communication such as newspapers and websites for public notice, and request for participation of individuals and groups (Glicken, 2000) are taken into account. Also, based on such criteria as legitimacy, power, and urgency (Mitchell et al., 1997), existence of expelled individuals and communities (Pierce Colfer and Dudley, 2011; Butler and Adamowski, 2015), individuals' interest levels, influence of the process, the level of project support (Sarriegi et al., 2006; Reed et al., 2009; Ormazabal, Rich and Sarriegi, 2012), and use of different methods such as stakeholders analysis, card-sorting, strategic perspectives analysis, $\mathrm{Q}$ methodology, and constructivist method (Reed et al., 2009; Richardson and Anderson, 2010), stakeholders are prioritized and selected to be invited to participate in the group model building. So, selecting people is purposeful (Yuliani and Tasrif, 2006). In some cases, contributors are members of the intended community. So, this method is referred to as 'community-driven participatory modeling method (Yadama et al., 2010; Homand et al., 2010). Prior to holding a workshop, the arrangements for it should be made and its activities should be planned. They include goal setting, procurement, timing or developing a precise time table for the workshop day, determining a convenient location and required facilities (including whiteboard, white wall, video projector, computer equipped with modeling software, proper arrangement of seats and appliances), and 
taking decisions about the use of work books (Anderson and Richardson, 1994; Tsuey-Ping et al., 1998; Luna-Reyes et al., 2005; Groesser, 2006; Hernantes et al., 2013; Butler and Adamowski, 2015).

In some cases, pre-workshop interviews with stakeholders to get their initial perspectives on structuring the problem (Berard, 2010) or even primary causal modeling as well as modeling the training may take place (Ford and Sterman, 1997; Butler and Adamowski, 2015).

Phase of modeling workshops (i.e. execution phase):

In group model building workshops, a facilitator who is usually a neutral person (Pieters, Franx and Akkermans, 2007; Vugteveen et al., 2015) guides a group of participants to make a model or a decision (Vennix, Thijssen and Rouwette, 1997, Papamichail et al., 2007; Franco and Montibeller, 2010). The workshop begins with a brief introduction of researchers and purposes of the study (Goh et al., 2012). Also, at first, the rules and procedures of modeling, such as conflict resolution and model implementation, should be explained (Vennix, 1999). Then, the workshop continues using the initial model or conceptual models to start a discussion followed by training of system dynamics modeling (Vennix, 1996; Groesser, 2006; Richardson, 2006; 2013).

Workshops usually evolve from individually-based activities into small groups and full groups (Anderson and Richardson, 1994; 1997). The purpose of the individual activities is mainly individual interviews or individual modeling. The purpose of small groups, namely small professionally heterogeneous groups with 2 to 3 members, is to work on details and run exact discussions on the problem and the model. Eventually, these individuals in small groups merge in full groups or plenary sessions where all the members are present for providing their achievements and debates on different perspectives, seeking to achieve convergence that leads to completed models (Vennix et al., 1990; Vennix, Thijssen and Rouwette, 1997; Ackermann et al., 2011; Hernantes et al., 2012; 2013). In many cases, large groups in workshops are broken down into small groups with specialized knowledge domains (Vennix et al., 1988; Akkermans and Bosker, 1994; Rich et al., 2009; Carter et al., 2013). Bartolomei and Miller (2001) and Olafsdottir et al., (2014) argue that 5-6 member teams are appropriate (Olafsdottir et al., 2014) and, if more members are required, it is better to perform modeling in the form of 3-4 member subgroups (Bartolomei and Miller, 2001).

In the workshops, attempts are made to integrate the tasks for running discussions and getting feedbacks about the causes, consequences and solutions (Halbe and Adamowski, 2011). Also, dialogues are held with various stakeholders to promote social learning and consensus (PahlWostl et al., 2011).

In the second phase, depending on the modeling goal, the participants go through the steps of problem definition, creation of hexagons, making quantitative and qualitative diagrams (e.g. causal loop diagrams and stock and flow diagrams), formulation, simulation and testing, implementation of various policies on the model, and finally drawing conclusions (Antunes et al., 2006; Cavana and Clifford, 2006; Elias, 2008b). The important point often neglected is model validation in group model building, where tests should be conducted with regard to the data and logic, individual and group mental models, and interactions between them in a system dynamics model (Happach et al., 2012; Bachurina, 2013).

Usually, in early steps, qualitative approaches and divergent thinking are used to extract information, but, in final steps, the focus is on quantitative approaches and convergent thinking (Richardson et al., 1989; Château et al., 2012).

Practical implications for group model building sessions include the need for enough time and resources to hold modeling sessions until completion of the project because a suitable model 
possibly cannot be built in a few days. Also, clients and participants should have motivation to spend sufficient time and attention in the sessions (Pagani and Otto, 2013).

The phase after the group model building workshops or the final phase:

After testing the model and selecting the proposed solutions, the results are presented to the client to implement them (Butler and Adamowski, 2015).

Finally, as Otto and Struben (2003) have stated, some researchers such as Vennix emphasize structured processes and precise approaches while some others such as Hines emphasize being heuristic.

\section{Different roles in group model building}

As noted, the modeling team undertakes the management of a group model building project by playing various roles (Haslett, Barton, Sarah, 1999). These roles include facilitating, moderating/recording, content coaching/modeling, process coaching, and gatekeeping (LunaReyes et al., 2005; Yahril et al., 2006; Anderson and Richardson, 2010; Esensoy and Carter, 2015). In other words, different roles are required to be played because group model building involves various tasks such as extracting information about the structure and behavior of problems, compiling information on the model, providing and explaining the model to the members, getting feedbacks, and modifying the model (Richardson et al., 1992). The role players are defined as follows:

A facilitator is someone who undertakes the task of knowledge extraction and facilitating the affairs in the group. Among his duties are continuous attention to the group process, the role of individuals in the group, and extracting knowledge and insights from the group. It is the most visible role working with the group.

A content coach/modeler does not focus on the whole process but mainly works on the model to be established clearly by the facilitator and the group. He helps both the facilitator and the group. This person thinks and draws ideas in the form of a model, reflects the information to the group, then reconstructs formulas and codifications, and expresses undeclared assumptions that need to be clarified. In general, the person is a catalyst of various aspects of the model structure and behavior.

The important point about both of the above roles is that the person concerned must be experienced in system dynamics modeling.

A process coach is a person who does not focus on the content but on individual and subgroup dynamics in the group. He is not a system dynamics modeler but mostly helps the facilitator.

A Recorder tries to write and draw important behavioral and expressive parts of the group. His writings, along with notes of the facilitator and the content coach, should cause reconstruction of group thinking. This person should have enough modeling knowledge as well as awareness of what things should be written.

A Gatekeeper is a person within or related to the clients' group who is responsible for the project with regard to the clients, usually starts the project, helps to define the problem and identify the right people, works with the modeling team to structure sessions, and participates as a member of the group. He is the supporters of both sides; within the organization, he talks about the modeling process and, within the modeling team, he talks about the client group and their problems. The gatekeeper is, indeed, someone rising from the organization with communicating tasks (Anderson and Richardson, 1994; Luna-Reyes et al., 2005). 
An important point about these five roles is that they can be combined and allocated among different individuals from the consultant to the members of the modeling team and clients. For example, Richardson et al., (1992) and Ackermann, Vennix and Rouwette (1993) allocated these five roles to three persons. However, according to the results of their research, for large groups, it is better that each role be played by one person (Richardson et al., 1992).

Finally, it must be noted that, typically, three distinct sets have roles to play in group model building. The first set is the core modeling group or the modeling team which deals with the project management, collection and analysis of data, simulations, etc. The second set includes clients and problem stakeholders serving as institutions or departments that have a significant responsibility in the desired problems. Finally, the third set consists of experts that are people with good knowledge about the problem (Richardson et al., 1992; Anderson and Richardson, 1994).

\section{Advantages and disadvantages of group model building}

According to various articles that have directly (17 articles) or indirectly expressed the results and features of group model building, there are many advantages to this method. Involvement and participation of stakeholders in modeling has various benefits such as extracting the correct information, organizing deep discussions, making more qualified decisions (Winz and Gary, 2007), giving a greater understanding of the problem and the structure that creates it, providing a more relevant useful model with the integration of stakeholder perspectives (Quade, 1982; Meadows and Robinson; 1985; Ackermann and Vennix, 1996; Vennix, 1996; Rouwette and Vennix, 1996; Chen et al., 2014), improving the policy solutions and efficiency of responses and measures (Ackermann, 1992; Pahl-Wostl and Hare, 2004), creating a positive insight for cooperation, strengthening mutual understanding, providing equal opportunity for all the groups, making a consensus on the model and solutions, increasing the sense of ownership and commitment to the model implementation (Vennix et al., 1990; Lane, 1993; Vennix and Scheper, 1993; Vennix, 1994, 1999; Ackermann and Vennix, 1996; Vennix et al., 1996; Rouwette and Vennix, 1996; 2010; Ford and Sterman, 1997; Zagonel, 2002; Otto and Simon, 2005; Kljajic Borstnar et al., 2006; Antunes et al., 2006; Qian and Gonzalez, 2006; Visser, 2006; Martinez-Moyano et al.,2007; Rouwette and Hoppenbrouwers, 2008; McCardle-Keurentjes, Rouwette and Vennix, 2009; Château et al., 2012; Pagani and Otto, 2013; Vugteveen et al., 2015; Scott, Cavana and Cameron, 2016), creating more innovative and equitable solutions, individuals, and groups, bringing about organizational and social learning (Winz and Gary, 2007; Carhart and Yearworth, 2010; Mikulskiene and Pitrenaite, 2012), sharing experiences, making mental models of stakeholders, achieving a shared vision (De Geus, 1988; Lin, 1992; Morecroft, 1988; 1992; Senge, 1990; Ackermann, 1992; Gary and Charyk, 1996; Vennix et al., 1996; Vennix, Thijssen and Rouwette, 1997; Haslett, Barton, Sarah, 1999; Ruud and Bakken, 2003; Stave and Dwyer, 2005; Groesser, 2006; Yahril et al., 2006; Voinov and Bousquet, 2010), improving communication and discussion among members (Eskinasi, Rouwette and Vennix, 2009; Schlyter et al., 2012), increasing reliance on model and its results (Pahl-Wostl and Hare, 2004; Olafsdottir et al., 2014; Vugteveen et al., 2015; Flynn, 2015), reducing bound rationality (Zimmermann et al., 2015), seeking a system by extracting and integrating the different perspectives of stakeholders and identification of feedback mechanisms, studying multifactor and multilevel relationships among system elements through simulation of an experimental learning environment, reaching a shared language, understanding and consensus (Lin, 1993; Vennix, 1996; Elias, 2008b; Schmitt Olabisi, 2010; Alexiev, 2011; Carter et al., 2013), and identifying and evaluating possible policy options (Munar et al., 2015; Butler and Adamowski, 2015; Hernantes et al., 2013). 
Group model building increases learning through two ways of clarifying the content related to a complex issue (i.e. reducing the technical complexity) and strengthening client commitment via a participatory approach (in relation to organizational complexity) (Roos, 1997).

In a research that Ackermann, Vennix and Rouwette (1993) conducted through direct questionnaires about knowledge, insight, knowledge sharing and commitment among participants before and after group model building, it was found that most participants would consider group model building successful in the strengthening of these four measures.

Vennix and Scheper (1993) evaluated the group model building method in four case studies. They suggest that, although various researchers have expressed important functions of models and group model building, no systematic review of this method has been much conducted yet. Via questionnaires, they investigated four aspects including 1) insights created in relation to the problem (learning), 2) facilitation of sharing mental models and communicating with the problem (communication), 3) creating shared understanding of the problem (shared understanding), and 4) strengthening of commitment (commitment). A Likert-type questionnaire was formulated for each of the four aspects consisting of 4 to 7 questions. In their study, it was found that all the participants in the group model building acknowledged its usefulness and importance, and most of them considered this method effective (Vennix and Scheper, 1993).

In his article, Vennix (1994) argues that group model building has been successful in integration of conflicting views, strengthening of consensus, and making a commitment. He states that, in this respect, there exist three effective factors including system thinking, improvement of the quality of communication, and the role of facilitator.

By reviewing the literature on group model building, Vennix, Ackermann and Rouwette (1996), Ackermann and Vennix (1997) and Rouwette et al., (2002) found that participants believe group model building leads to an improvement in the quality of communication, insight, consensus and commitment to results.

Comparing two methods of problem solving including group model building system dynamics and traditional group process, Dwyer and Stave (2008) found that system dynamics provides a better foundation for structural discussions, extracting mental models and making the correct decisions. According to their findings, group model building has a better performance both in the process and in the output variable but is slightly poor in the input variable.

Rouwette, Bleijenbergh and Vennix (2014) argue that, in relation to messy problems in a general multi-organizational field, group model building is filled with ambiguity and contradiction, which leads to open communication as well as changes in insight and quality of the results. According to the findings of a review of literature by Rouwette et al. $(2011,2012)$, the efficiency of group model building can be discussed at four levels including individual, group, organizational and method levels at the individual level, one is concerned with cognitive changes such as positive reaction, purification mental model, insight, commitment to decisions, and behavior changes. The group level involves group behavior, such as increasing the quality of commitment, developing a shared language, and coming to a consensus. At the organizational level, the significance is given to changes in the system and improvement of the system or its results. The method/efficiency level refers to the more efficient use of time and resources for acquisition of individual and group effects (Rouwette et al., 2009). It is argued that group model building possibly cannot have organizational effects, because it is not mentioned in the literature (Scott, Cavana and Cameron, 2016). Apart from this finding about the 4-level efficiency proposed by Rouwette et al., (2012), Scott, Cavana and Cameron, (2016) have achieved some other new results regarding persuasion, decision quality, power leveling, and group cohesion. They have indicated that persuasion is created both in the outcome and in the mechanism of group model 
building. Decision quality is measurable on the basis of the participants, the number of variables considered, and the elaboration of problem topics to solutions. Power leveling analyzes the interaction between individuals, where people with less power can participate in group model building and discussions (Nistelrooij et al., 2012). Their study shows that consensus, commitment, power leveling and persuasion are more of a concern in group model building than in traditional sessions. In addition, compared to traditional methods, tacit, or hidden, knowledge sharing is of more significance in group model building, but sharing understanding and communication or commitment plays a better role in some studies than in others. They also argue that, according to their findings, the output of group model building can be improved better and faster than that of traditional sessions.

In a previous study, Scott, Cavana and Cameron (2014) had investigated the results of group model building. Also, further back, Scott et al. (2012) had administered questionnaires to 52 participants within four modeling workshops to find that the quality of communication, insight, consensus and commitment would increase, and modeling outputs might be achieved faster and better than in conventional workshops. These results are consistent with Herrera (2014). It was also found that open communication and model ownership are critical components the group model building in terms of respondents. In other studies, Scott, Cavana and Cameron (2013a, 2013b) found continuous changes in mental models and the resulting insights.

Hovelynck et al. (2010) suggest that extraction of knowledge in transdisciplinary fields through group model building overcomes three dualities of simplicity versus complexity, constraining versus containing, and defining versus refining.

In the assessment of group model building, Fokkinga, Bleijenbergh and Vennix (2009) state that building a model in a group increases the knowledge of participants in relation to the number of effective variables, leading to an increase of learning. However, learning about feedback processes in a group is not much more than learning achieved through written studying and modeling. According to those researchers, this may be because, in causal loop modeling, the communication is through images rather than words, knowledge about feedback is not increased immediately after drawing it, and mental model does not change as soon.

Vugteveen et al. (2015) state that group model building has advantages such as method flexibility, transparency, capability of integrating quantitative and qualitative information, ability to integrate a wide range of parameters in a meaningful way (demonstrating the inherent interactions and feedbacks), explicit recognition of the multiple forms of uncertainty, serving as a tool to involve stakeholders, knowledge sharing, and exchange of individual perspectives. According to them, this method has limitations as well. As an example, the answer is in the room. In other words, the input in this method is participants' understanding and their mental model, but there is not an opportunity to check them with actual data and statements or various data sources.

Finally, in their review studies of group model building, Rouwette, Vennix and Mullekom (1999; 2002) indicated that group model building improves insight, commitment, quality of communication, consensus, behavioral changes and changes in the systems but does not support shared language.

However, the participation of stakeholders in the whole process has some disadvantages, including the need to spend more time, resources, and efforts (Winz and Gary, 2007; Hovmand et al., 2010; Butler and Adamowski, 2015). Wagle (2014) proposed rapid participatory system dynamics modeling (RPSDM) approach to meet the challenge of limitations of time and resources and provide expertise which is based on combining individual and group model building methods in three rounds. Also, in group sessions, in case of dominance of a particular individual 
or group, there may be no correct discussion to present or no chance for the model to be taken with a consensus (Hernantes et al., 2013). In such cases, the sessions fail to benefit from collective or group thinking (Hovmand et al., 2010).

\section{Findings in terms of methodology}

The summary results of previous papers in terms of methodology are provided in Table 1. According to the table, as many as 87 papers are in the form of case studies, seeking to solve or recognize a problem. Papers with empirical methods are in the next place, mainly seeking to assess the results of these methods. Conceptual expansion of group model building through descriptive methods and viewpoints of the experts of these methods are in the third place.

Table 1. Summary findings from the review of previous studies in terms of methodology

\begin{tabular}{|l|c|c|c|c|}
\hline \multicolumn{1}{|c|}{ Research Method } & $\begin{array}{c}\text { No. of } \\
\text { articles in } \\
\text { Elsevier }\end{array}$ & $\begin{array}{c}\text { No. of papers } \\
\text { in SD } \\
\text { Conference }\end{array}$ & $\begin{array}{c}\text { No. of } \\
\text { articles in } \\
\text { Wiley }\end{array}$ & Total \\
\hline Exploratory empirical study & 2 & 2 & 1 & 3 \\
\hline comparative analysis & 1 & 6 & 2 & 2 \\
\hline Systematic Review & 1 & 6 & 1 & 8 \\
\hline Technical report & 1 & 1 & 6 & 8 \\
\hline $\begin{array}{l}\text { Viewpoint, Editorial, NOTES } \\
\text { AND INSIGHTS }\end{array}$ & 15 & 56 & 16 & 87 \\
\hline Case study & 1 & 5 & 3 & 8 \\
\hline Survey & 2 & 5 & 1 & 13 \\
\hline Experimental & 1 & 1 & & 9 \\
\hline Action Research & & 2 & & 2 \\
\hline Grounded theory & & 9 & 1 & 10 \\
\hline conceptual work & $\mathbf{2 4}$ & $\mathbf{1 0 4}$ & $\mathbf{3 3}$ & $\mathbf{1 6 1}$ \\
\hline Description & & & \\
\hline \multicolumn{1}{|c|}{ Total } & & & & 8 \\
\hline
\end{tabular}

Findings in terms of modeling type and model output (artifact)

The summary results of previous papers in terms of modeling type are given in Table 2. According to the table, most such studies have been conducted with no modeling. In other words, their focus has been more on theorizing and improving group model building.

Table 2. Summary findings from the review of previous studies in terms of modeling type

\begin{tabular}{|c|c|c|c|c|}
\hline Modeling type & $\begin{array}{c}\text { No. of articles } \\
\text { in Elsevier }\end{array}$ & $\begin{array}{c}\text { No. of papers in } \\
\text { SD Conference }\end{array}$ & $\begin{array}{c}\text { No. of } \\
\text { articles in } \\
\text { Wiley }\end{array}$ & Total \\
\hline Quantitative & 6 & 25 & 9 & 40 \\
\hline
\end{tabular}




\begin{tabular}{|c|c|c|c|c|}
\hline Qualitative & 11 & 24 & 2 & 37 \\
\hline No modeling & 6 & 54 & 19 & $\mathbf{7 9}$ \\
\hline Total & $\mathbf{2 3}$ & $\mathbf{1 0 3}$ & $\mathbf{3 0}$ & $\mathbf{1 5 6}$ \\
\hline
\end{tabular}

In a review article about the steps of involving stakeholders in group model building, Rouwette, Vennix and Mullekom $(1999 ; 2002)$ express that most acts of modeling come to an end in the conceptualization step, but, in all or a part of the steps, studies have used client involvement. In other words, the majority of articles are qualitative. However, in our research, as the graph below shows, the percentage of articles written on qualitative modeling and quantitative modeling is equal.

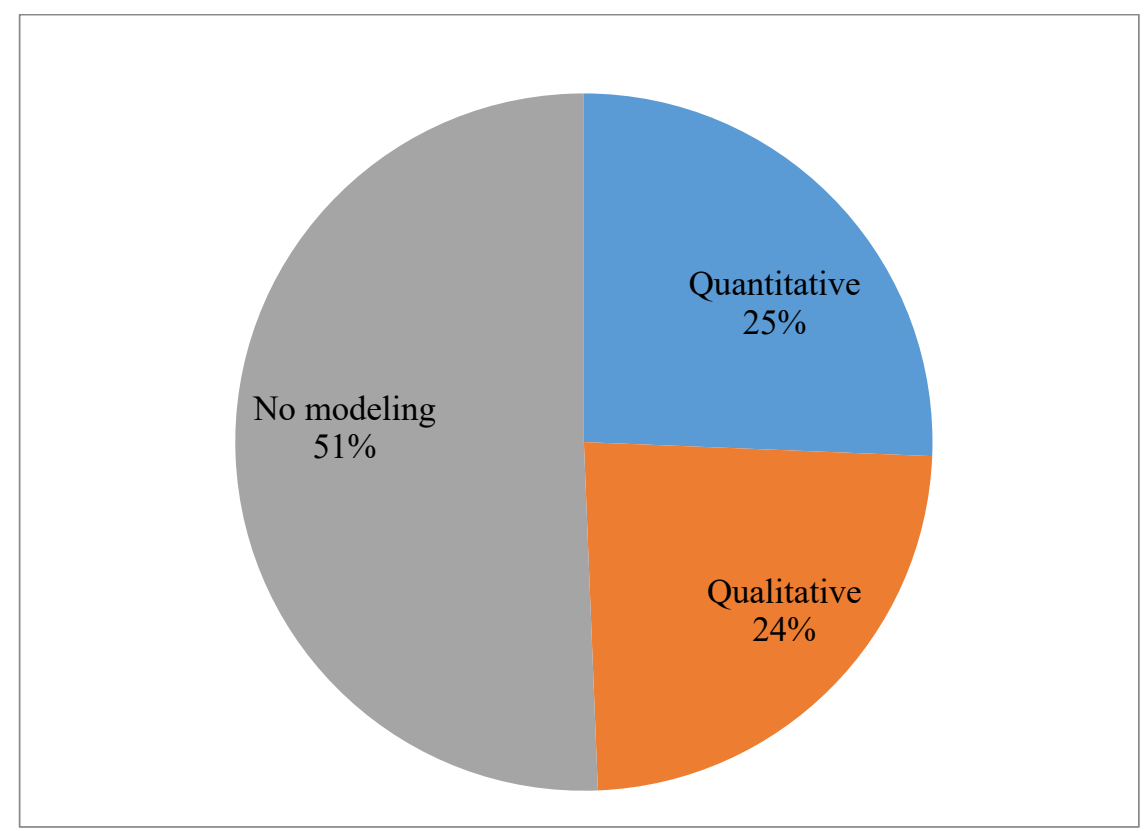

Figure 2. Percentage of articles by the type of modeling

The table below shows the output of the modeling, or the article artifacts. As the case is, most of the articles did not have any specific output in terms of artifacts, and this is consistent with previous findings based on the focus of articles on theorizing and improving the group model building method.

Table 3. Summary findings from the review of previous studies in terms of output (artifact)

\begin{tabular}{|c|c|c|}
\hline $\begin{array}{c}\text { Ro } \\
\mathbf{w}\end{array}$ & Output (artifact) & $\begin{array}{c}\text { No. of } \\
\text { articles }\end{array}$ \\
\hline 1 & Improvement suggestions for participation & 1 \\
\hline 2 & Stock and Flow diagram (simulation model) & 41 \\
\hline 3 & Causal loop diagram (conceptual model) & 35 \\
\hline 4 & Scripts Map / scriptpedia & 6 \\
\hline 5 & Provide methods to quantify variables & 1 \\
\hline 6 & Confirm findings related to the effectiveness of group model \\
building & 2 \\
\hline 7 & The initial structure for simulation on the Web & 1 \\
\hline
\end{tabular}


Journal of Business School, vol.3, issue.3, pp.98-136

\begin{tabular}{|c|c|c|}
\hline 8 & Introduction to Groupware Technology & 1 \\
\hline 9 & No specific output & 68 \\
\hline & Total & 156 \\
\hline
\end{tabular}

The great thing about their articles and their output is that, out of 156 desired articles, around 17 have examined the effectiveness of group model building, suggesting that this area is one of the key areas to study more.

\section{Survey works in terms of application or modeling area}

To review the articles from the viewpoint of the fields of application of group model building, they may be divided into 5 categories of organization and business, group model building, environment, health care, and public sector. In the figure below, the share of each of these areas has been identified. About 72 percent of the papers have sought to solve a problem, which is consistent with the statement of Rouwette, Vennix and Mullekom (1999) in that about 75 percent of studies aim at applied solutions.

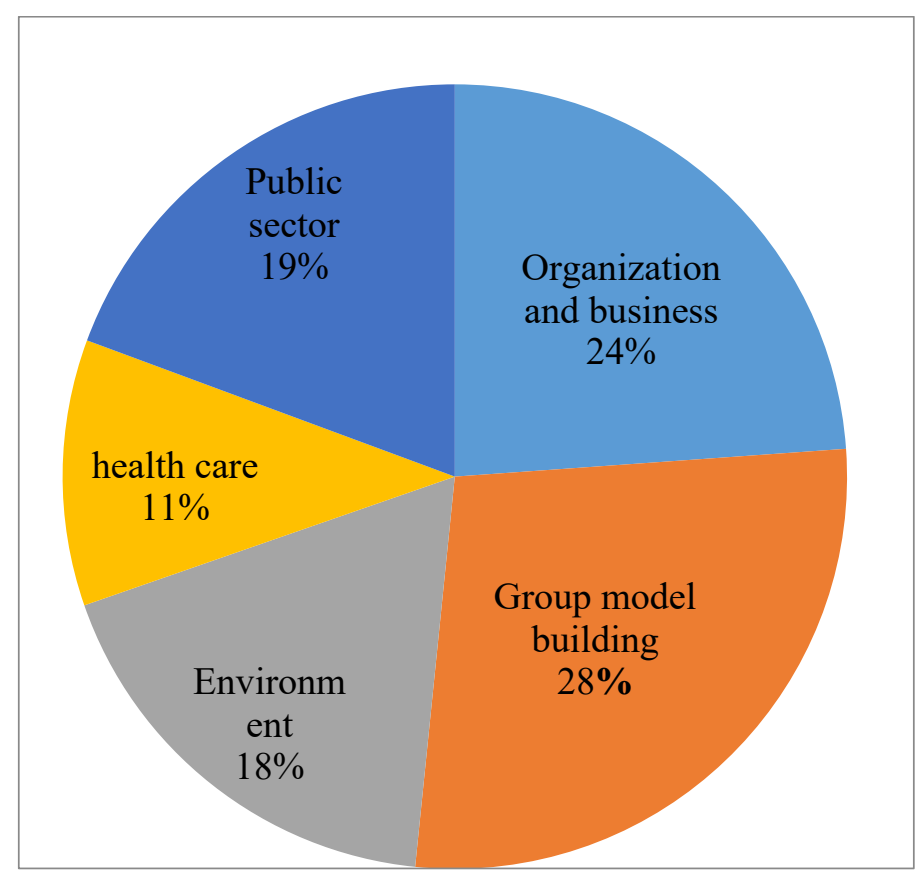

Figure 3. Percentage of article breakdown in terms of application field

In Tables 4 through 8, these areas and subareas are presented separately for a number of articles. As it can be seen in Table 4, in the field of business, the greatest contribution is related to organizational strategic planning.

Table 4. Summary findings from the review of previous studies on group model building in terms of business area

\begin{tabular}{|l|l|l|}
\hline \multicolumn{3}{|c|}{ organization and business } \\
\hline Row & Subareas of application & $\begin{array}{l}\text { No. } \\
\text { article }\end{array}$ \\
\hline
\end{tabular}


Journal of Business School, vol.3, issue.3, pp.98-136

\begin{tabular}{|c|c|c|}
\hline 1 & Life Cycle Assessment & 1 \\
\hline 2 & Organizational strategic planning & 11 \\
\hline 3 & Management and organizational structure & 5 \\
\hline 4 & Planning and information systems & 5 \\
\hline 5 & Decision-making and education & 3 \\
\hline 6 & Production and Operations Management & 5 \\
\hline 7 & Police human resource management & 1 \\
\hline 8 & Various industries (fisheries, banking, nuclear, military, tourism, etc.) & 6 \\
\hline & Total & 37 \\
\hline
\end{tabular}

According to Table 5, in connection with the articles that have explained and developed group model building in terms of methodology and its various aspects, most of the articles are related to the scripts and assessment of group model building.

Table 5. Summary findings from the review of previous studies on group model building in terms of group model building

\begin{tabular}{|c|c|c|}
\hline \multicolumn{2}{|c|}{ Group model building (GMB) } \\
\hline Row & Subareas of application & No. article \\
\hline 1 & GMB methodology and scripts & 24 \\
\hline 2 & GMB Assessment & 10 \\
\hline 3 & Validation in GMB & 2 \\
\hline 4 & System Dynamics Training & 2 \\
\hline 5 & Stakeholder analysis in GMB & 1 \\
\hline 6 & Mental models in GMB & 2 \\
\hline 7 & GMB and combination with other methods & 1 \\
\hline 8 & GMB and visual display tools & 1 \\
\hline 9 & Communication theory and Facilitation in GMB & 1 \\
\hline & Total & $\mathbf{4 4}$ \\
\hline
\end{tabular}

Table 6. Summary findings from the review of previous studies on group model building in terms of environment area

\begin{tabular}{|l|l|l|}
\hline \multicolumn{3}{|c|}{ Environment } \\
\hline Row & Subareas of application & No. article \\
\hline
\end{tabular}


Journal of Business School, vol.3, issue.3, pp.98-136

\begin{tabular}{|l|c|c|}
\hline 1 & Environmental management and natural resources & 10 \\
\hline 2 & Energy & 4 \\
\hline 3 & Adaptive management in natural resources and climate & 2 \\
\hline 4 & water resource management & 6 \\
\hline 5 & Management of forest resources & 3 \\
\hline 6 & Support decisions in wildlife management & 2 \\
\hline 7 & Transport and environment issues & 1 \\
\hline & Total & $\mathbf{2 8}$ \\
\hline
\end{tabular}

Table 7. Summary findings from the review of previous studies on group model building in terms of health care

\begin{tabular}{|c|c|c|}
\hline \multicolumn{2}{|c|}{ Health care } \\
\hline Row & Subareas of application & No. article \\
\hline 1 & Health care systems policymaking & 11 \\
\hline 2 & Culture management and safety in Health & 1 \\
\hline 3 & World's infant mortality problems & 1 \\
\hline 4 & Insurance and health care system & 1 \\
\hline 5 & The paradox in primary care & 1 \\
\hline 6 & Health system and hospital management & 1 \\
\hline 7 & Justice in oral health for the elderly & 1 \\
\hline & Total & 17 \\
\hline
\end{tabular}

Tables 6,7 , and 8, present the articles related to the field of environment, health care, and policymaking in the public sector. Since there are other aspects of significance in the field of group model building, a lot of articles have also analyzed and solved problems in such areas as stakeholders, high complexity, and long-term effects,

Table 8. Summary findings from the review of previous studies on group model building in terms of public area

\begin{tabular}{|c|c|c|}
\hline \multicolumn{2}{|c|}{ Public area } \\
\hline Row & Subareas of application & No. article \\
\hline 1 & Criminal and Justice issues & 3 \\
\hline 2 & Social Welfare & 4 \\
\hline 3 & Sustainable Development & 2 \\
\hline 4 & Transportation Management and municipalization & 5 \\
\hline 5 & Policymaking and public strategy & 7 \\
\hline 6 & IT in the public sector & 2 \\
\hline 7 & Crisis management and critical infrastructure & 2 \\
\hline 8 & Social issues & 5 \\
\hline
\end{tabular}




\begin{tabular}{|c|c|c|}
\hline & Total & 30 \\
\hline
\end{tabular}

Findings in terms of the number of participants in group sessions

In a review paper on group model building, Rouwette, Vennix and Mullekom $(1999,2002)$ refer to time and the number of people involved in modeling sessions. As they state, in most articles, participation in face-to-face interactions is reported to be with 5 to 12 and maximally 22 people, which is a very small number. However, more people, 30 to 70, are reported to participate in subgroups. As for the time of participation, it is reported to be from two full days to five years, but two to four workshops are found to last from one full day to two or three hours.

As it is clear from Fig. 4, the number of participants ranges from four to 66 while most articles have reported four to 12 participants, which is consistent with the results of Rouwette, Vennix and Mullekom $(1999,2002)$.

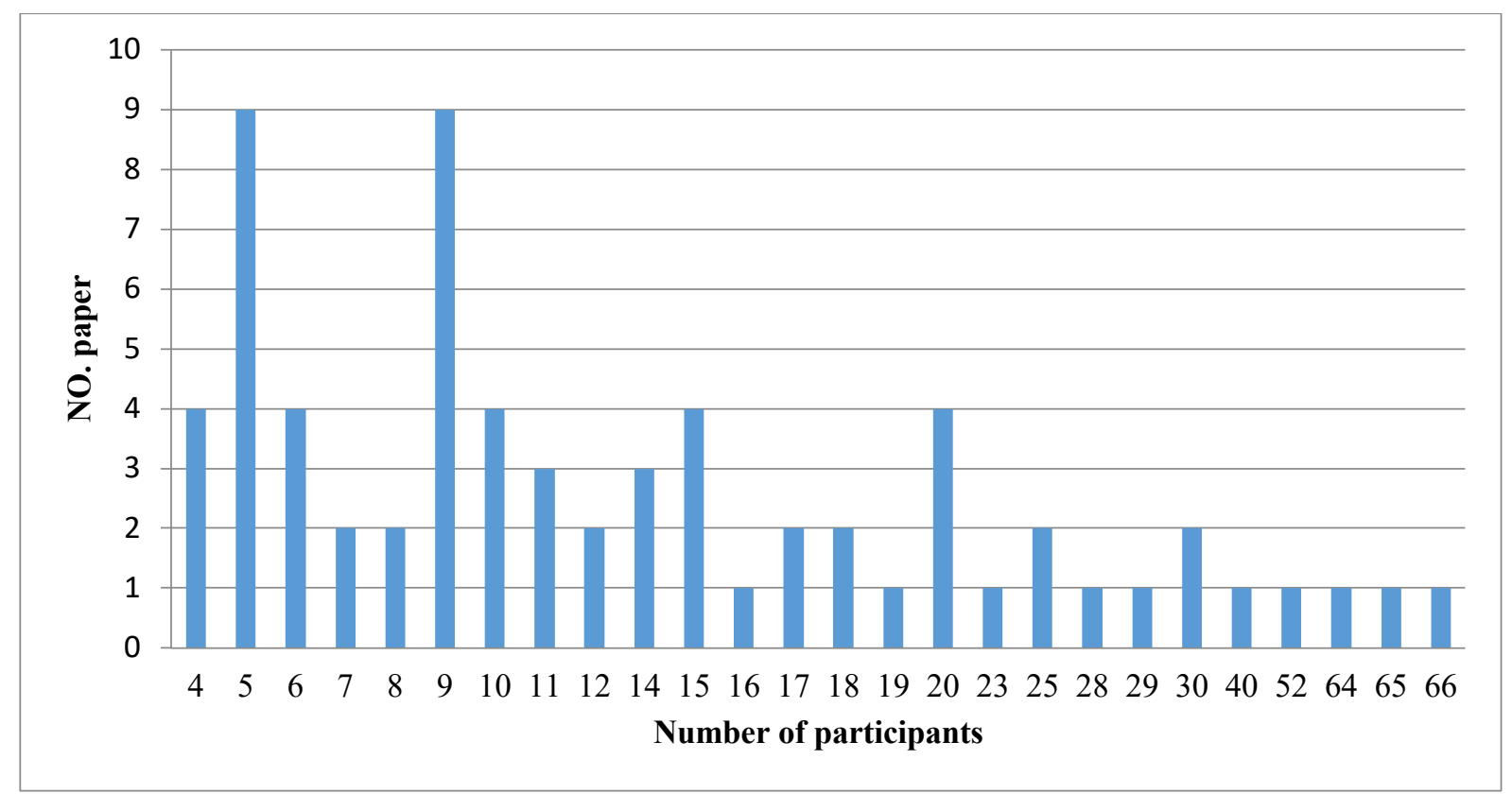

Figure 4. Summary findings from the review of previous studies on group model building in terms of the number of participants

In the table below, three categories are provided in terms of the number of participants in modeling sessions. As it can be seen, the greatest number of articles is related to small groups $(0$ to 12 people). The average number of participants in these groups is eight. These categories also show that a full group (i.e. a large group with more than 25 participants) has been used in a few articles.

Table 9. The average number of participants in small, medium and full groups

\begin{tabular}{|l|c|c|c|}
\hline & Range (participants) & Average participants & No. of articles \\
\hline Small group & $0-12$ & 8 & 39 \\
\hline Medium group & $12-25$ & 18 & 20 \\
\hline
\end{tabular}




\begin{tabular}{|l|c|c|c|}
\hline Full group & more than 25 & 45 & 9 \\
\hline
\end{tabular}

\section{Findings in terms of geographical regions}

The summary findings from the review of previous studies in terms of geographical regions are provided in Table 10 and Fig. 5. As suggested, about 50 percent of the studies on group model building (i.e. 78 papers) are conducted in Europe.

Table 10. Summary findings from the review of previous studies in terms of geographical regions

\begin{tabular}{|c|c|c|c|c|}
\hline $\begin{array}{c}\text { Geographical } \\
\text { region }\end{array}$ & $\begin{array}{c}\text { No. of articles } \\
\text { in Elsevier }\end{array}$ & $\begin{array}{c}\text { No. of papers in SD } \\
\text { Conference }\end{array}$ & $\begin{array}{c}\text { No. of articles in } \\
\text { Wiley }\end{array}$ & Total \\
\hline Europe & 13 & 49 & 16 & 78 \\
\hline Asia and others & 6 & 19 & 3 & 28 \\
\hline $\begin{array}{c}\text { Canada and } \\
\text { America }\end{array}$ & 4 & 35 & 11 & 50 \\
\hline Total & $\mathbf{2 3}$ & $\mathbf{1 0 3}$ & $\mathbf{3 0}$ & $\mathbf{1 5 6}$ \\
\hline
\end{tabular}

By examining the regional distribution, it is clear that more than 58 percent of the studies have been conducted in the Netherlands. This is attributed to the specific activities of Delft and Radboud Universities as well as the European program of system dynamics in which several universities are engaged for teaching and research in the field.

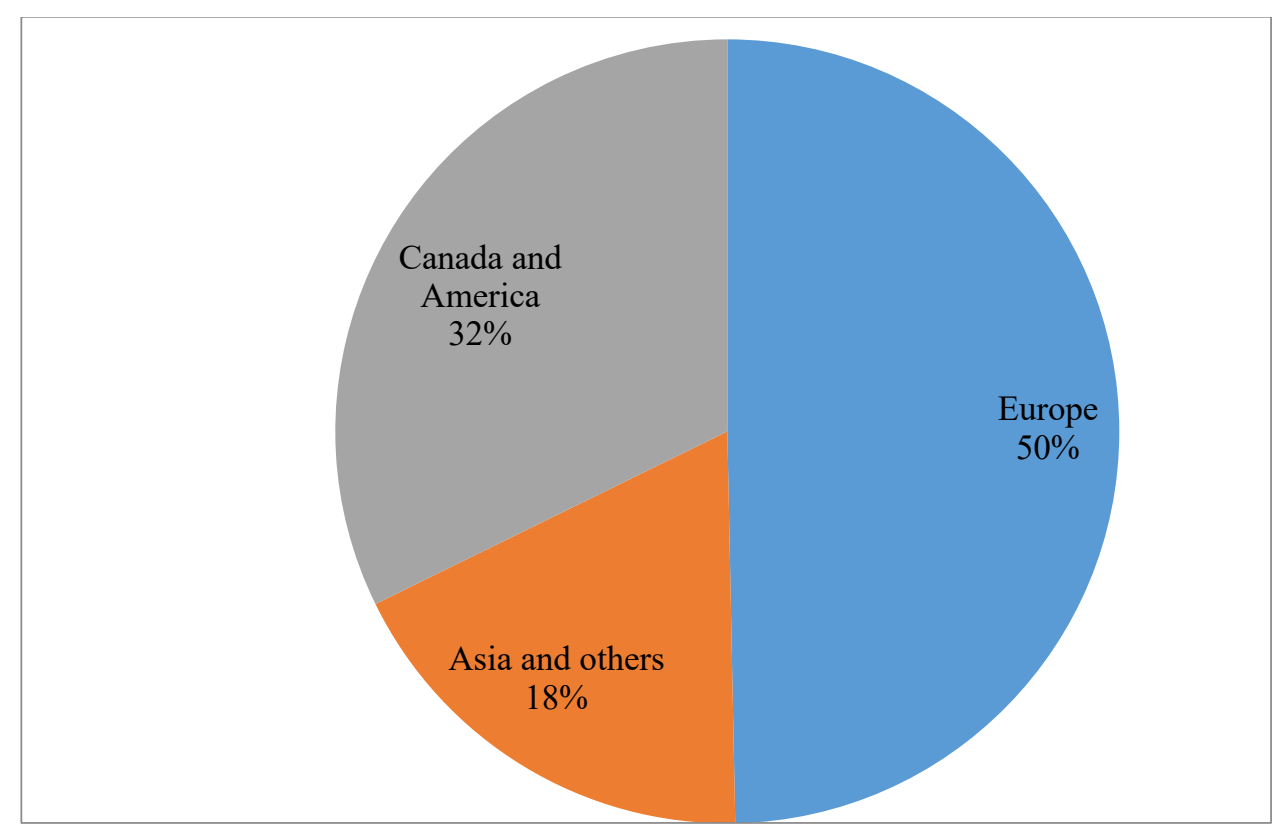

Figure 5. Graphic view of the summary findings from the review of previous studies in terms of geographical regions

According to the table below, in Australia as well as in some Asian countries such as New Zealand and India, good work has been done in the field. Also, in terms of the number of papers, the USA and the Netherlands are in the first two places, implying that these two countries are the cradles of the approach.

Table 11. Summary findings from the review of previous studies in terms of regional and national geographical distribution 
Journal of Business School, vol.3, issue.3, pp.98-136

\begin{tabular}{|c|c|c|}
\hline Geographical region & No. of articles & Frequency (\%) \\
\hline Asia and others & 28 & $100 \%$ \\
\hline Australia & 9 & $32 \%$ \\
\hline Taiwan & 2 & $7 \%$ \\
\hline New Zealand & 8 & $29 \%$ \\
\hline Philippines & 1 & $4 \%$ \\
\hline India & 5 & $18 \%$ \\
\hline Indonesia & 2 & $7 \%$ \\
\hline Japan & 1 & $4 \%$ \\
\hline Canada and America & 50 & $100 \%$ \\
\hline America (USA) & 46 & $92 \%$ \\
\hline Canada & 2 & $4 \%$ \\
\hline Mexico & 2 & $4 \%$ \\
\hline Europe & 78 & $100 \%$ \\
\hline Spain & 3 & $4 \%$ \\
\hline Germany & 6 & $8 \%$ \\
\hline England & 8 & $10 \%$ \\
\hline Italy & 1 & $1 \%$ \\
\hline Belgium & 1 & $1 \%$ \\
\hline Portugal & 1 & $1 \%$ \\
\hline Sweden & 2 & $3 \%$ \\
\hline Norway & 4 & $5 \%$ \\
\hline Netherlands & 45 & $58 \%$ \\
\hline Slovenia & 1 & $1 \%$ \\
\hline Swiss & 3 & $4 \%$ \\
\hline Iceland & 1 & $1 \%$ \\
\hline Russia & 2 & $3 \%$ \\
\hline
\end{tabular}

\section{Findings in terms of the relevant journals}

Table 12 reports the summary findings from the review of previous studies in terms of the number of papers published in each of the relevant journals. In this regard, the two journals of System Dynamics Review (with 22 articles) and Systems Research and Behavioral Science (with 7 articles) have published the highest number of articles.

Table 12. Summary findings from the review of previous studies in terms of the relevant journals

\begin{tabular}{|c|c|}
\hline Journal & No. of articles \\
\hline Accident Analysis and Prevention & 1 \\
\hline Computers, Environment and Urban Systems & 1 \\
\hline
\end{tabular}


Journal of Business School, vol.3, issue.3, pp.98-136

\begin{tabular}{|c|c|}
\hline Energy Policy & 1 \\
\hline Environmental Modelling \& Software & 2 \\
\hline Environmental Science \& Policy & 2 \\
\hline European Journal of Operational Research & 1 \\
\hline Expert Systems with Applications & 103 \\
\hline International Conference of the System Dynamics Society & 1 \\
\hline International Journal of Critical Infrastructure Protection & 1 \\
\hline Journal of Business Research & 2 \\
\hline Journal of Cleaner Production & 2 \\
\hline Journal of Environmental Management & 1 \\
\hline Knowledge and Process Management & 1 \\
\hline Land Use Policy & 1 \\
\hline Ocean \& Coastal Management & 1 \\
\hline Omega & 1 \\
\hline Operations Research for Health Care & 1 \\
\hline Procedia Computer Science & 155 \\
\hline Science of The Total Environment & 7 \\
\hline SEMINARSIN PERINATOLOGY & 1 \\
\hline System Dynamics Review & 1 \\
\hline Systems Research and Behavioral Science & 1 \\
\hline Technological Forecasting and Social Change & 1 \\
\hline
\end{tabular}

The table below presents the types of papers published in the field. As it can be seen, System Dynamics Conference accounts for the highest number of articles.

Table 13. Summary findings from the review of previous studies in terms of article type

\begin{tabular}{|c|c|}
\hline Paper Type & No. of articles \\
\hline Conference paper & 95 \\
\hline Conference paper-abstract & 9 \\
\hline Journal paper & 49 \\
\hline Editorial & 3 \\
\hline Total & $\mathbf{1 5 6}$ \\
\hline
\end{tabular}

\section{Conclusion}

Since the designing of the system dynamics approach by Forrester in the 1950s, different methods, tools, software programs, processes, and information resources have been provided for system dynamics modeling. From the beginning of the emergence of this approach, Forrester has emphasized the importance of involving clients in system dynamics modeling. In this regard, 
various methods are developed, such as individual interviews (individual modeling), collaborative model building, and group model building.

Group model building is a participatory method to extract knowledge from clients, stakeholders and the studied problem experts through face-to-face and official meetings. This may involve tasks ranging from problem definition to model simulation and offering solutions.

Since it emerged, the group model building method has been rapidly expanding, such that it is practically applied by many researchers. Considering the necessity of reviewing the studies ever done on group model building from the viewpoints of both its tenets and instructions and of other aspects that have not been studied yet, this paper aims at a comprehensive review of the literature related to the group model building method. In this study, through a systematic review of 156 articles published until 2017 on group model building, we summed up the studies conducted on this issue by identifying the focuses of attention of researchers represented in definitions of the group model building method, the type of problems suitable for this method, outputs of group model building, group model building processes, different roles in group model building, advantages and disadvantages of group model building, survey works in terms of methodology, survey works in terms of modeling types, survey works in terms of application or modeling areas, survey works in terms of the number of participants in group sessions, survey works in terms of geographical regions, and survey works in terms of the related journals.

Based on the literature review, it was found that implementation of this approach requires certain conditions, and, thus, it is not suitable for every problem. However, transdisciplinary messy problems with dynamic complex pluralist situations are suitable for this approach. Depending on the type of the problem and the goal of modeling, the output of this approach may be classified into three categories. According to the conducted study, most articles have not had a specific output in terms of artifacts, implying a focus of those papers on theorizing and improving the group model building method and providing new scripts to improve the modeling process. It was also found that articles with quantitative outputs are of the same percentage as those with qualitative outputs and causal diagrams.

According to the review of the papers, it was found that three distinct sets of people are generally involved in group model building including the core modeling group or the modeling team, clients and stakeholders, and experts. These individuals typically play different roles in group model building sessions.

Many articles have pointed to the benefits of this approach. Most articles have listed some benefits such as better understanding of problems, individual and group learning, open communication and involvement of people with different power levels, providing better solutions with consensus, and greater commitment to implement those solutions. However, in some of the reviewed articles, certain disadvantages have been expressed such as the need to spend a lot of time and money and group thinking challenges.

It was also found that the major bulk of research is in the form of case studies with 87 papers seeking to solve or recognize a problem. In addition, about 17 papers have examined the effectiveness of group model building. In terms of the application areas of group model building, we can classify the papers into five categories of organization and business, group model building, environment, health care, and public sector. The highest share in the articles belongs to strategic fields and development of methodology for group model building. In terms of the number of participants in modeling sessions, three categories of small, medium, and full group were created. The highest number of articles is related to small groups ( 0 to 12 people). In these groups, the average number of participants is 8 . This classification also indicates that full groups (i.e. large groups with more than 25 participants) have been used in a few articles. 
Finally, it is obvious that the use of group model building is expanding due to the complex nature of problems in the world today.

\section{Reference}

Ackermann, Fran, David F. Andersen, Colin Eden, George P. Richardson, 2010, Using a group decision support system to add value to group model building, System Dynamics Review vol 26, No 4 (October-December 2010): 335-346.

Ackermann, Fran, et al. 2011. "ScriptsMap: A tool for designing multi-method policy-making workshops." Omega 39(4): 427-434.

Adamides, Emmanuel, Nikos Karacapilidis, 2005, Knowledge Management and Collaborative Model Building in the Strategy Development Process, Knowledge and Process Management Volume 12 Number 2 pp 77-88 (2005).

Akkermans, Henk A., Jac A. M. Vennix, 1997, Clients' opinions on group model-building: an exploratory study, System Dynamics Review Vol. 13, No. 1, (Spring 1997): 3-31.

Akkermans, Henk with Jac Vennix, 1996, Clients' Opinions on Group Model-Building: An Exploratory Study, The 14th International Conference of the System Dynamics Society, 1996 Cambridge, Massachusetts, USA.

Akkermans, Henk with Jac Vennix, Etiënne Rouwette, 1993, Participative Modeling To Facilitate Organizational Change: A Case Study, The 11th International Conference of the System Dynamics Society, 1993 Cancun, Mexico.

Akkermans, Henk with Jacqueline Bosker, 1994, Design Guidelines for Participative Business Modelling projects: lessons from an unsuccessful case study, The 12th International Conference of the System Dynamics Society, 1994 Stirling, Scotland.

Akkermans, Henk, 1992, Participative Modeling to Support Strategic Decision Making in Operations - A Case Study, The 10th International Conference of the System Dynamics Society,1992 Utrecht, Netherlands.

Akkermans, Henk, 1995, Quantifying the Soft Issues: A Case Study in the Banking Industry, The 13th International Conference of the System Dynamics Society, 1995 Tokyo, Japan.

Akkermans, Henk, 2001, Renga: A systems approach to facilitating inter-organizational network development, System Dynamics Review Vol. 17, No. 3, (Fall 2001): 179-193.

Alexiev, Victor, 2012, MEASURING GROUP MODEL BUILDING INTERVENTION IMPACT THROUGH PREFERENCE ELICITATION, The 30th International Conference of the System Dynamics Society, July 22 - 26, 2012, St. Gallen, Switzerland.

Allyson Beall and Andrew Ford, 2007, Participatory Modeling for Adaptive Management: Reports from the Field II, The 2007 International Conference of the System Dynamics Society and 50th Anniversay Celebration, July 29 - August 2, 2007, Boston, Massachusetts, USA.

Amelia, Dea Fitri, Dominik Jung, Veronika Iurchenko, 2014, ANALYSIS OF PROJECT MANAGEMENT PROCESSES AT A DUTCH PUBLIC INFRASTRUCTURE AGENCY USING GROUP MODEL BUILDING, 32nd International Conference of the System Dynamics Society, Delft, Netherlands -- July 20-24, 2014.

Andersen, D.F., J.A.M. Vennix, G.P. Richardson, E. Rouwette, 2007, Group model building: problem structuring, policy simulation and decision support, J. Oper. Res. Soc. (2007) 691694. 
Andersen, David F., George P. Richardson, 1997, Scripts for group model building, System Dynamics Review Vol. 13, No. 2, (Summer 1997): 107-129.

Andersen, David F., George P. Richardson, 2010, Improvised Facilitation: A Third Leg on the Group Model Building Stool, The 28th International Conference of the System Dynamics Society, July $25-29$, 2010, Seoul, Korea.

Andersen, David F., George P. Richardson, Jac A. M.Vennix, 1997, Group model building: adding more science to the craft, System Dynamics Review, Vol. 13, No. 2, (Summer 1997): 187-201.

Andersen, David with George Richardson, Colin Eden and Fran Ackermann, 2009a, ScriptsMap: A Tool for Designing Multi-Method Strategy Workshops, The 27th International Conference of the System Dynamics Society, July 26 - 30, 2009, Albuquerque, New Mexico, USA.

Andersen, David with George Richardson, Colin Eden and Fran Ackermann, 2009b, Using Stakeholder Goals and Dynamics to Surface Feedback Loops, The 27th International Conference of the System Dynamics Society, July 26 - 30, 2009, Albuquerque, New Mexico, USA.

Anderson, David F., et al., 2013, Scriptapedia: Version 4.0.6, The 31st International Conference of the System Dynamics Society, July 21 - July 25, 2013 Cambridge, Massachusetts USA.

Anderson, David F., George P. Richardson, 1994, Scripts for Groups Model Building, The 12th International Conference of the System Dynamics Society, 1994 Stirling, Scotland.

Antunes, Paula, et al. (2006). "Participatory decision making for sustainable development-the use of mediated modelling techniques." Land Use Policy 23(1): 44-52.

Bachurina, Anna, 2013, Model validation: matching data and structure to behavior through partial model calibration in Group Model Building setting, The 31st International Conference of the System Dynamics Society, July 21 - July 25, 2013 Cambridge, Massachusetts USA.

Bartolomei, J. E.; T. Miller, 2001, Functional Analysis Systems Technique (F.A.S.T.) as a Group Knowledge Elicitation Method for Model Building, The 19th International Conference of The System Dynamics Society, July 23 - 27, 2001, Emory Hotel and Conference Center, Atlanta, Georgia, USA.

Bayer, Steffen, Timothy Bolt, Maria Kapsali, Sally Brailsford, 2010, The social role of simulation models, The 28th International Conference of the System Dynamics Society, July 25 - 29, 2010, Seoul, Korea.

Beall, Allyson with Andrew Ford and Len Zeoli, 2006, Participatory Modeling of Endangered Wildlife Systems: Simulating the Sage-grouse and Land Use in Central Washington, The 24th International Conference of the System Dynamics Society, July 23-27, 2006 Nijmegen, The Netherlands.

Berard, C., 2010. Group model building using system dynamics: an analysis of methodological frameworks. Electron. J. Bus. Res. Methods 8 (1), 35e45.

Black, Laura J., 2013, When visuals are boundary objects in system dynamics work, System Dynamics Review vol 29, No 2 (April-June 2013): 70-86. 
Black, Laura J., David F. Andersen, 2012, Using Visual Representations as Boundary Objects to Resolve Conflict in Collaborative Model-Building Approaches, Systems Research and Behavioral Science, 29, 194-208 (2012).

Bleijenbergh, Inge, Brigit Fokkinga, 2013, Increasing part-time working hours in the Netherlands. Identifying policy recommendations through Group Model Building, The 31st International Conference of the System Dynamics Society, July 21 - July 25, 2013 Cambridge, Massachusetts USA.

Brömmelstroet, Marco te, 2013. "Performance of Planning Support Systems: What is it, and how do we report on it?", Computers, Environment and Urban Systems 41(0): 299-308.

Butler, Cameron and Jan Adamowski 2015. "Empowering marginalized communities in water resources management: Addressing inequitable practices in Participatory Model Building." Journal of Environmental Management 153(0): 153-162.

Calhoun, Annaliese, Peter Hovmand, David Andersen, George Richardson, Timothy Hower, \& Etiënne Rouwette, 2010, Scriptapedia: A Digital Commons for Documenting and Sharing Group Model Building Scripts, The 28th International Conference of the System Dynamics Society, July 25 - 29, 2010, Seoul, Korea.

Carhart, Neil, Mike Yearworth, 2010, The Use of System Dynamics Group Model Building for Analysing Event Causality within the Nuclear Industry, The 28th International Conference of the System Dynamics Society, July 25 - 29, 2010, Seoul, Korea.

Carter, David, et al. 2013. "Using groups to support judgmental parameter estimation VISCONS: 'Eyeballing' to capture a quantified group consensus." Expert Systems with Applications 40(2): 715-721.

Cavana, Robert Y, Thomas H. Adams, 2010, A Qualitative System Dynamics Analysis of the Effects of an Emissions Trading Scheme on the New Zealand Forestry Value Chain, The 28th International Conference of the System Dynamics Society, July 25 - 29, 2010, Seoul, Korea.

Cavana, Robert Y., Leslie V. Clifford, 2006, Demonstrating the utility of system dynamics for public policy analysis in New Zealand: the case of excise tax policy on tobacco, System Dynamics Review Vol. 22, No. 4, (Winter 2006): 321-348.

Cavana, Robert Y., Trecia Smith, Rodney J. Scott \& Shaun O'Connor, 2014, Causal Mapping of the New Zealand Natural Resources Sector System: A Preliminary Analysis, 32nd International Conference of the System Dynamics Society, Delft, Netherlands -- July 20-24, 2014.

Château, Pierre-Alexandre, et al. (2012). "Building a stakeholder's vision of an offshore windfarm project: A group modeling approach." Science of The Total Environment 420(0): 43-53.

Checkland, P., Scholes, J., 1999. "Soft Systems Methodology in Action". Wiley, Chichester.

Chen, Hsin, et al. 2014. "Integrated wetland management: An analysis with group model building based on system dynamics model." Journal of Environmental Management 146(0): 309-319.

Coyle, G., (1999). "Qualitative modelling in system dynamics or what are the wise limits of quantification?". In: Proceedings of the System Dynamics, Wellington, New Zealand.

David F. Andersen, George P. Richardson, Fran Ackermann, Colin Eden, 2007, Two Group Model Building Scripts that Integrate Systems Thinking (using Vensim) into Strategy 
Workshops (using Group Explorer), The 2007 International Conference of the System Dynamics Society and 50th Anniversay Celebration, July 29 - August 2, 2007, Boston, Massachusetts, USA.

De Geus AP., 1988. Planning as learning. Harvard Business Review (March/April): 70-74.

De Gooyert, Vincent with Etiënne Rouwette and Hans van Kranenburg, 2013, Reviewing the Role of Stakeholders in Operational Research: Opportunities for Group Model Building, The 31st International Conference of the System Dynamics Society, July 21 - July 25, 2013, Cambridge, Massachusetts USA

Doyle, James K. with David N. Ford, 1997, Mental Models Concepts for System Dynamics Research, The 15th International Conference of the System Dynamics Society, August 1922, 1997 --- Istanbul, Turkey.

E.A.J.A. (Etiënne) Rouwette, S.J.B.A. (Stijn) Hoppenbrouwers, 2008, Collaborative systems modeling and group model building: a useful combination?, The 2008 International Conference of the System Dynamics Society, July 20 - 24, 2008 , Athens, Greece.

Eden, C., F. Ackermann, 2006, Where next for problem structuring methods, J. Oper. Res. Soc. 57 (2006) 766-768.

Elias, A.A., 2008a. Towards a shared systems model of stakeholders in environmental conflict. International Transactions in Operational Research 15, 239e253.

Elias, Arun A., Robert Y. Cavana, Laurie S. Jackson, 2004, Analysing stakeholder dynamics in environment conflict: a new Zealand transport infrastructure project, The 22th International Conference of The System Dynamics Society, July 25 - 29, 2004 --- Keble College, Oxford, England.

Elias, Arun Abraham, 2008b. "Energy efficiency in New Zealand's residential sector: A systemic analysis." Energy Policy 36(9): 3278-3285.

Elias, Arun, 2006, Environmental Conflicts, Stakeholders and a Shared Mental Model, The 24th International Conference of the System Dynamics Society, July 23-27, 2006 Nijmegen, The Netherlands.

Esensoy, A. V. and M. W. Carter, 2015. "Health system modelling for policy development and evaluation: Using qualitative methods to capture the whole-system perspective." Operations Research for Health Care 4(0): 15-26.

Eskinasi, Martijn, Etienne Rouwette, Jac Vennix, 2009, Simulating urban transformation in Haaglanden, the Netherlands, System Dynamics Review Vol. 25, No. 3, (July-September 2009): 182-206.

Etiënne A.J.A. Rouwette, Jac A.M. Vennix, 2010, Improving operations management by synthesizing participant knowledge and system data, The 28th International Conference of the System Dynamics Society, July 25 - 29, 2010, Seoul, Korea.

Flynn, D. N. 2015. "Building a Better Model: A Novel Approach for Mapping Organisational and Functional Structure." Procedia Computer Science 44(0): 194-203.

Fokkinga, Brigit, Inge Bleijenbergh, Jac Vennix, (2009), Group model building evaluation in single cases: a method to assess changes in mental models, The 27th International Conference of the System Dynamics Society, July 26 - 30, 2009, Albuquerque, New Mexico, USA. 
Ford, Andrew with Allyson Beall and Len Zeoli, 2006, Participatory Modeling for Adaptive Management: Reports from the Field, The 24th International Conference of the System Dynamics Society, July 23-27, 2006 Nijmegen, The Netherlands.

Ford, David N. with John D. Sterman, 1997, Expert Knowledge Elicitation to Improve Mental and Formal Models, The 15th International Conference of the System Dynamics Society, August 19-22, 1997 --- Istanbul, Turkey.

Forrester, J.W. 1961.Industrial dynamics. Cambridge: The MIT Press.

Franco, L.A., Montibeller, G., 2010. "Facilitated modelling in operational research". European Journal of Operational Research 205 (3), 489-500.

Franco, Maria, 2014, Seeking Implementation in Group Model Building Interventions, 32nd International Conference of the System Dynamics Society, Delft, Netherlands -- July 20-24, 2014.

Funtowicz, S., Ravetz, J., 1994. The worth of a songbird: ecological economics, as a post-normal science. Ecological Economics 10, 197-207.

Garrod, G., Raley, M., Aznar, O., Espinosa, O.B., et al., 2013. Engaging stakeholders through participatory modelling. Proc. Inst. Civ. Eng. 166 (ES2), 75e84.

Gary, Shane with Chris Charyk, 1996, Using Groupware Technology to Facilitate Team Model Building and Learning, The 14th International Conference of the System Dynamics Society, 1996 Cambridge, Massachusetts, USA.

Geeske Scholz, Martina Austermann, Kai Kaldrack, Claudia Pahl-Wostl, 2015, Evaluating group model building exercises: a method for comparing externalized mental models and group models, System Dynamics Review vol 31, No 1-2 (January-June 2015): 28-45.

Glicken, J., 2000. Getting stakeholder participation 'right': a discussion of participatory processes and possible pitfalls. Environ. Sci. Policy 3, 305e310.

Goh, Y.M., Brown, H., Spickett, J., 2010a. "Applying systems thinking concepts in the analysis of major incidents and safety culture". Safety Science 48, 302-309.

Goh, Y.M., Love, P.E.D., Brown, H., Spickett, J.T., 2010b."Organizational accidents: a systemic model of production versus protection". Journal of Management Studies, in press, doi:10.1111/j.1467-6486.2010.00959.x.

Goh, Yang Miang, et al. 2012. "Dynamics of safety performance and culture: A group model building approach." Accident Analysis \& Prevention 48(0): 118-125.

Groesser, Stefan, 2006, Development of a Group Model Building Framework, The 24th International Conference of the System Dynamics Society, July 23-27, 2006 Nijmegen, The Netherlands.

Hager, Gerid M., Birgit Kopainsky, Progress H. Nyanga, 2015, Learning as conceptual change during community based group interventions. A case study with smallholder farmers in Zambia, 33rd International Conference of the System Dynamics Society, Cambridge, Massachusetts, USA, July 19-23, 2015.

Halbe, J., Adamowski, J., 2011. Use of participatory system dynamics modelling for collaborative watershed management in Quebec, Canada. J. Agric. Eng. 48 (2), $21 \mathrm{e} 29$. 
Halbe, Johannes, et al. 2015, "The Role of Paradigms in Engineering Practice and Education for Sustainable Development." Journal of Cleaner Production (2015), doi: 10.1016/j.jclepro.2015.01.093.

Happach, R.M., G.A. Veldhuis, J.A.M. Vennix, E.A.J.A. Rouwette, 2012, Group Model Validation, The 30th International Conference of the System Dynamics Society, July 22 26, 2012, St. Gallen, Switzerland.

Haslett, Tim, John Barton, Rod Sarah, 1999, The Use of Group Modelling Techniques as a Teaching Tool, The 17th International Conference of The System Dynamics Society and the 5th Australian \& New Zealand Systems Conference, July 20 - 23, 1999 --- Wellington, New Zealand.

Hernantes, J., L. Labaka, A. Lauge, J.M. Sarriegi, J.J. Gonzalez,2012, Group Model Building: A collaborative modelling methodology applied to critical infrastructure protection, Int. J. Organ. Des. Eng. 2 (2012) 41-60.

Hernantes, Josune, et al. 2013. "Learning before the storm: Modeling multiple stakeholder activities in support of crisis management, a practical case." Technological Forecasting and Social Change 80(9): 1742-1755.

Herrera, Hugo, 2014, Combining group decision support systems and participatory system dynamics to create strategic dynamic statements, 32nd International Conference of the System Dynamics Society, Delft, Netherlands -- July 20-24, 2014.

Hovelynck, Johan, et al. 2010. "Interdisciplinary knowledge integration through group model building: recognizing dualities and triadizing the conversation." Environmental Science \& Policy 13(7): 582-591.

Hovmand, Peter S., David F. Andersen, Etiënne Rouwette, George P. Richardson, Krista Rux, Annaliese Calhoun, 2012, Group Model-Building 'Scripts' as a Collaborative Planning Tool, Systems Research and Behavioral Science, 29, 179-193 (2012).

Hovmand, Peter S., Eënne A. J. A. Rouwette, 2013, Scriptapedia4.0:A Tool for Designing "Scripted" Group Model Building Workshops, The 31st International Conference of the System Dynamics Society, July 21 - July 25, 2013 Cambridge, Massachusetts USA.

Hovmand, Peter S., Eënne A. J. A. Rouwette, 2014, Scriptapedia 5.0:A Tool for Designing "Scripted" Group Model Building Workshops, 32nd International Conference of the System Dynamics Society, Delft, Netherlands -- July 20-24, 2014.

Hovmand, Peter S., et al., (2011), Scriptapedia: A Handbook of Scripts for Developing Structured Group Model Building Sessions, The 29th International Conference of the System Dynamics Society, July $25-29,2011$, Washington, DC.

Hovmand, Peter S., Gautam Yadama, Nishesh Chalise, Annaliese Calhoun, Daniel Conner, 2010, Combining Group Model Building and Participatory Rural Appraisal in Southeast Rural India, The 28th International Conference of the System Dynamics Society, July 25 29, 2010, Seoul, Korea.

Hovmand, Peter with Etiënne Rouwette, 2015, Scriptapedia: Introduction to "Scripted" Group Model Building Workshops, 33rd International Conference of the System Dynamics Society, Cambridge, Massachusetts, USA, July 19-23, 2015.

Hovmand, Peter with Mary Scheetz, Tony Robinson and Krista Rux, 2011, Using Group Model Building to Introduce High School Students to System Dynamics, The 29th International Conference of the System Dynamics Society, July 25 - 29, 2011, Washington, DC. 
Hovmand, Peter with Nathaniel Osgood, Alison Kraus, Jill Kuhlberg, Ross Hammond, Kristen Hassmiller Lich, Anindita Biswas, Kurt Stange and Johnie Rose, 2014, Extending Group Model Building to Agent Based Modeling: A Case Study on Understanding the Paradox of Primary Care, 32nd International Conference of the System Dynamics Society, Delft, Netherlands -- July 20-24, 2014.

Howick, Susan, Fran Ackermann and David Andersen, 2006, Linking event thinking with structural thinking: methods to improve client value in projects, System Dynamics Review Vol. 22, No. 2, (Summer 2006): 113-140.

Inam, A., Adamowski, J., Halbe, J., Prasher, S., Zaman, Q., 2015. Using causal loop diagrams for the initialization of stakeholder engagement in soil salinity management in agricultural watersheds in developing countries: a case study in the Rechna Doab watershed, Pakistan. J. Environ. Manage. 152, 251e267.

Kim, Hyunjung, 2007, IN SEARCH OF A MENTAL-MODEL-LIKE CONCEPT FOR GROUP LEVEL MODELING, The 2007 International Conference of the System Dynamics Society and 50th Anniversay Celebration, July 29 - August 2, 2007, Boston, Massachusetts, USA.

Kljajic Borstnar, Mirjana with Andrej Skraba, Miroljub Kljajic and Davorin Kofjac, 2006, Group Learning Supported by Simulation model an Experiment Design, The 24th International Conference of the System Dynamics Society, July 23-27, 2006 Nijmegen, The Netherlands.

Kuhlberg, Jill A., Jeanine Arrighi, Cindy Pulley, William Kincaid, 2013, Process Insights from Using Group Model Building to Address Emergency Department Use for Pediatric Asthma Treatment, The 31st International Conference of the System Dynamics Society, July 21 - July 25, 2013 Cambridge, Massachusetts USA.

Kuhlberg, Jill, 2015, Theory Development in Group Model Building: Progress and Insights, 33rd International Conference of the System Dynamics Society, Cambridge, Massachusetts, USA, July 19-23, 2015.

Kum, Susan S., et al., 2015, Boundary Objects for Group Model Building to Explore Oral Health Equity, 33rd International Conference of the System Dynamics Society, Cambridge, Massachusetts, USA, July 19-23, 2015.

Lane DC., 1992. Modelling as learning: A consultancy methodology for enhancing learning in management teams. In Modelling for learning, special issue of European Journal of Operational Research (Morecroft TDW, Sterman JD (eds)) 59(1): 64-84.

Lane, David C., 1993, From Discussion To Dialogue : How an interactive modeling process was used with managers to resolve conflict and generic meaning, The 11th International Conference of the System Dynamics Society, 1993 Cancun, Mexico.

Laurenti, Rafael, et al. 2014. "Group Model-Building to identify potential sources of environmental impacts outside the scope of LCA studies." Journal of Cleaner Production 72(0): 96-109.

Linnéusson, Gary and Tehseen Aslam, 2014, Machine Strategy Evaluation Using Group Model Building in System Dynamics, 32nd International Conference of the System Dynamics Society, Delft, Netherlands -- July 20-24, 2014.

Luna-Reyes, Luis F., et al., 2013, Group Model Building to Support Interdisciplinary Theory Building, The 31st International Conference of the System Dynamics Society, July 21 - July 25, 2013 Cambridge, Massachusetts USA. 
Luna-Reyes, Luis F., Laura J. Black, Anthony M. Cresswell, Theresa A. Pardoc, 2008, Knowledge sharing and trust in collaborative requirements analysis, System Dynamics Review Vol. 24, No. 3, (Fall 2008): 265-297.

Luna-Reyes, Luis Felipe, Deborah Lines Andersen, 2003, Collecting and analyzing qualitative data for system dynamics: methods and models, System Dynamics Review Vol. 19, No. 4, (Winter 2003): 271-296.

Luna-Reyes, Luis Felipe, et al., 2004, Scripts for Interrupted Group Model Building: Lessons from Modeling the Emergence of Governance Structures for Information Integration Across Government Agencies, The 22th International Conference of The System Dynamics Society, July 25 - 29, 2004 --- Keble College, Oxford, England.

Luna-Reyes, Luis Felipe, Ignacio J. Martinez-Moyano, Theresa A. Pardo, Anthony M. Cresswell, David F. Andersen, George P. Richardson, 2006, Anatomy of a group model-building intervention: building dynamic theory from case study research, System Dynamics Review Vol. 22, No. 4, (Winter 2006): 291-320.

Luna-Reyes, Luis with Ignacio Martinez-Moyano, Theresa Pardo, Anthony Cresswell, David Andersen and George Richardson, 2005, Group Modeling of IT-Based Innovations in the Public Sector, The 23rd International Conference of the System Dynamics Society, July 1721, 2005 Boston.

Martinez-Moyano, Ignacio J., Stephen Conrad, Andrew Cox, Chris Krahe, 2007, Modeling Aviation Security Processes: A Group Model Building Approach, The 2007 International Conference of the System Dynamics Society and 50th Anniversay Celebration, July 29 August 2, 2007, Boston, Massachusetts, USA.

McCardle-Keurentjes, Marleen H.F., Etiënne A.J.A. Rouwette, Jac A.M. Vennix, 2008, Effectiveness of Group Model Building in discovering hidden profiles in strategic decision-making, The 2008 International Conference of the System Dynamics Society, July 20 - 24, 2008 , Athens, Greece.

McCardle-Keurentjes, Marleen H.F., Etiënne A.J.A. Rouwette, Jac A.M. Vennix, Eric Jacobs, 2009, Is Group Model Building worthwile? Considering the effectiveness of GMB, The 27th International Conference of the System Dynamics Society, July 26 - 30, 2009, Albuquerque, New Mexico, USA.

Meadows, Donella H., and J. M. Robinson., 1985. The Electronic Oracle, Computer Models and Social Decision. Chichester: John Wiley \& Sons.

Michael Dwyer, Krystyna Stave, 2008, Group Model Building Wins: The results of a comparative analysis, The 2008 International Conference of the System Dynamics Society, July $20-24,2008$, Athens, Greece.

Mikulskiene, Birute, Birute Pitrenaite, 2012, Participatory policy modelling for operational policy stream: the stakeholders and public administration perspective, The 30th International Conference of the System Dynamics Society, July 22 - 26, 2012, St. Gallen, Switzerland.

Mitchell, R.K., Alge, B.R., Wood, D.J., 1997. Towards a theory of stakeholder identification and salience: defining the principle of who and what really counts. Acad. Manag. Rev. 22 (4), $853 \mathrm{e} 886$. 
Morecroft JDW., 1992. Executive knowledge, models and learning. In Modelling for Learning, special issue of the European Journal of Operational Research (Morecroft JDW, Sterman JD (eds)) 59(1): 9-27.

Morecroft, JDW, 1988. System Dynamics and microworlds for policymakers. In: European Journal of Operational Research, vol. 35, 1988, 301-320.

Munar, Wolfgang, et al., 2015, Scaling-up impact in perinatology through systems science: Bridging the collaboration and translational divides in cross-disciplinary research and public policy, SEMINARSIN PERINATOLOGY, 39 (2015)416 - 423.

Nistelrooij, L.P.J. van, E.A.J.A. Rouwette, I.M. Verstijnen, J.A.M. Vennix, 2012, Power-leveling as an effect of group model building, The 30th International Conference of the System Dynamics Society, July 22 - 26, 2012, St. Gallen, Switzerland.

Nistelrooij, Lambertus P. J. van, Etiënne A.J.A. Rouwette, Ilse M. Verstijnen, Jac A.M. Vennix, 2015, The Eye of the Beholder: A Case Example of Changing Clients' Perspectives Through Involvement in the Model Validation Process, Systems Research and Behavioral Science, 32, pp 437-449 (2015).

Olabisi, Laura Schmitt, 2013, Participatory Modeling in Environmental Systems, The 31st International Conference of the System Dynamics Society, July 21 - July 25, 2013 Cambridge, Massachusetts USA.

Olafsdottir, Anna Hulda, Gunnar Stefansson, Helgi Thor Ingason, 2014, The value of Stakeholder Group Model-Building when facing a System Dynamic problem A qualitative research about methodological approach to form a CLD, 32nd International Conference of the System Dynamics Society, Delft, Netherlands -- July 20-24, 2014.

Ormazabal, Marta, Eliot Rich, Jose M. Sarriegi, 2012, Exploring Environmental Management Evolution through Maturity States and Behavior Over Time Graphs, The 30th International Conference of the System Dynamics Society, July 22 - 26, 2012, St. Gallen, Switzerland.

Otto, Peter with Martin Simon, 2005, Growing Ownership and Instilling Confidence for a Decision Support Approach at the Stakeholder Level, The 23rd International Conference of the System Dynamics Society, July 17-21, 2005 Boston.

Otto, Peter, Jeroen Struben, 2003, The "standard method": Scripts for a group model building intervention, The 21th International Conference of The System Dynamics Society, July 20 - 24, 2003, New York City, New York, U.S.A.

Ottoa, Peter, Jeroen Struben, 2004, Gloucester Fishery: insights from a group modeling intervention, System Dynamics Review Vol. 20, No. 4, (Winter 2004): 287-312.

Pagani, Margherita and Peter Otto, 2013. "Integrating strategic thinking and simulation in marketing strategy: Seeing the whole system." Journal of Business Research 66(9): 1568-1575.

Pahl-Wostl, C. 2007. "The implications of complexity for integrated resources management." Environmental Modelling \& Software 22(5): 561-569.

Pahl-Wostl, C., Hare, M., 2004. Processes of social learning in integrated resources management. J. Appl. Community Psychol. 14, 193e206.

Pahl-Wostl, C., Jeffrey, P., Isendahl, N., Brugnach, M., 2011. Maturing the new water management paradigm: progressing from aspiration to practice. Water Resour. Manag. 25 (3), 837e856. 
Papamichail, K.N., Alves, G., French, S., Yang, J.B., Snowdon, R., (2007). "Facilitation practices in decision workshops". Journal of the Operational Research Society 58 (5), 614-632.

Peter Wagner \& Associates, 2010. Safety: A Wicked Problem.

Pierce Colfer, Carol J., Richard G. Dudley, 2011, Strengthening Links Between Anthropologists and System Dynamicists: Participatory Group Modeling \& Natural Resources, The 29th International Conference of the System Dynamics Society, July 25 - 29, 2011, Washington, DC.

Pieters, Angèle, Arie Franx, Henk Akkermans,2007, Using group model building with many interdependent organizations to create integrated health care networks, The 2007 International Conference of the System Dynamics Society and 50th Anniversay Celebration, July 29 - August 2, 2007, Boston, Massachusetts, USA.

Powell, Beth Louisa, Bhakti Stephan Onggo, 2014, The Dynamics of Public Trust in a Business Organisation: Perspective from a Focus Group of Business Consultants, 32nd International Conference of the System Dynamics Society, Delft, Netherlands -- July 20-24, 2014.

Qian, Ying with Jose Gonzalez, 2006, Adapting Group Model Building Methods to Improve Information Security Data, The 24th International Conference of the System Dynamics Society, July 23-27, 2006 Nijmegen, The Netherlands.

Quade, E.S., 1982. Analysis for public decisions. New York/Amsterdam/Oxford, 1982 (2nd edition).

Reed, M.S., Graves, A., Dandy, N., Posthumus, H., et al., 2009. Who's in and why? A typology of stakeholder analysis methods for natural resource management. J. Environ. Manag. 90, $1933 \mathrm{e} 1949$.

Renger, M., G. Kolfschoten, G. de Vreede, 2008, Challenges in collaborative modeling: a literature review, in: Advances in Enterprise Engineering I, 2008, pp. 61-77.

Rettel, H.W.J., Webber, M.M., 1973. "Dilemmas in a general theory of planning". Policy Sciences $4,155-169$.

Rich, Eliot, et al. 2009. "Emergent vulnerabilities in Integrated Operations: A proactive simulation study of economic risk." International Journal of Critical Infrastructure Protection 2(3): 110-123.

Richards, R., et al. 2013. "Bayesian belief modeling of climate change impacts for informing regional adaptation options." Environmental Modelling \& Software 44(0): 113-121.

Richardson, George P. with David F. Andersen, John Rohrbaugh, William Steinhurst, 1992, Group Model Building, The 10th International Conference of the System Dynamics Society, 1992 Utrecht, Netherlands.

Richardson, George P. with Jac A.M. Vennix, David M. Anderson, John Rohrbaugh and W.A. Wallace, 1989, Eliciting Group Knowledge for Model-Building, The 7th International Conference of the System Dynamics Society, 1989 Stuttgart, Germany.

Richardson, George P., 2013, Concept models in group model building, System Dynamics Review vol 29, No 1 (January-March 2013): 42-55.

Richardson, George, 2006, Concept Models, The 24th International Conference of the System Dynamics Society, July 23-27, 2006 Nijmegen, The Netherlands. 
Richardson, GP and DF Andersen, 2010, Stakeholder Dynamics, The 28th International Conference of the System Dynamics Society, July 25 - 29, 2010, Seoul, Korea.

Romanenko, Eduard, 2014, Building Shared Vision As a Project Management Strategy: Quantitative model for a Qualitative Problem Context, 32nd International Conference of the System Dynamics Society, Delft, Netherlands -- July 20-24, 2014.

Roos, Egbert, 1997, Group Model Building with a Client Using System Dynamics Modeling, The 15th International Conference of the System Dynamics Society, August 19-22, 1997 --Istanbul, Turkey.

Rouwette, Etïenne A. J. A., Jac A. M. Vennix, Theo van Mullekom, 2002, Group model building effectiveness: review of assessment studies, System Dynamics Review Vol. 18, No. 1, (Spring 2002): 5-45.

Rouwette, Etiënne A. J. A., 2012, Does Group Model Building Work? Evidence from and Comments on the Paper by Videira et al., Systems Research and Behavioral Science, 29, 620-623 (2012).

Rouwette, Etiënne A. J. A., Hubert Korzilius, Jac A. M. Vennix, Eric Jacobs, 2011, Modeling as persuasion: the impact of group model building on attitudes and behavior, System Dynamics Review vol 27, No 1 (January-March 2011): 1-21.

Rouwette, Etiënne A.J.A., Jac A.M. Vennix, Theo van Mullekom, 1999, Gruop Model Building A review of assessment studies, The 17th International Conference of The System Dynamics Society and the 5th Australian \& New Zealand Systems Conference, July 20 - 23, 1999 --Wellington, New Zealand.

Rouwette, Etienne with Jac Vennix, 1996, The Influence of Group Model Building on Policy Intentions, The 14th International Conference of the System Dynamics Society, 1996 Cambridge, Massachusetts, USA.

Rouwette, Etiënne, Inge Bleijenbergh, Jac Vennix, 2014, Group Model-Building to Support Public Policy: Addressing a Conflicted Situation in a Problem Neighbourhood, Systems Research and Behavioral Science, (2014).

Rouwette, Etienne, Wouter Jongebreur, Paul van Hooff, Twan Heijmen, Jac Vennix, 2004, Modeling crime control in the Netherlands, The 22th International Conference of The System Dynamics Society, July 25 - 29, 2004 --- Keble College, Oxford, England.

Ruud, Morten, Bjørn Tallak Bakken, 2003, Development of multiplayer games through group modeling, The 21th International Conference of The System Dynamics Society, July 20 24, 2003, New York City, New York, U.S.A.

Sarriegi, Jose Mari with Javier Santos, José Manuel Torres, David Imizcoz and Angel Plandolit, 2006, Modeling Security Management of Information Systems: Analysis of a Ongoing Practical Case, The 24th International Conference of the System Dynamics Society, July 2327, 2006 Nijmegen, The Netherlands.

Schlüter, Maja, et al. 2010. "Coping with change: responses of the Uzbek water management regime to socio-economic transition and global change." Environmental Science \& Policy 13(7): 620-636.

Schlyter, Peter, Ingrid Stjernquist, Harald Sverdrup, 2012, Handling Complex Environmental Issues - Formal Group Modelling as a Deliberative Platform at the Science-PolicyDemocracy Interface, The 30th International Conference of the System Dynamics Society, July $22-26$, 2012, St. Gallen, Switzerland. 
Schmitt Olabisi, Laura, 2010, The System Dynamics of Forest Cover in the Developing World: Researcher vs. Community Perspectives, The 28th International Conference of the System Dynamics Society, July 25 - 29, 2010, Seoul, Korea.

Scott, Rodney J, Robert Y Cavana, Donald Cameron, 2013a, Evaluating long-term impact of qualitative system dynamics workshops on participant mental models, The 31st International Conference of the System Dynamics Society, July 21 - July 25, 2013 Cambridge, Massachusetts USA.

Scott, Rodney J, Robert Y Cavana, Donald Cameron, 2016, Recent evidence on the effectiveness of group model building, European Journal of Operational Research, 249 (2016) 908-918.

Scott, Rodney J., et al., 2012, Evaluation of group model building in a strategy implementation context: a New Zealand government case study, The 30th International Conference of the System Dynamics Society, July 22 - 26, 2012, St. Gallen, Switzerland.

Scott, Rodney J., Robert Y. Cavana, Donald Cameron, 2013b, Evaluating immediate and longterm impacts of qualitative group model building workshops on participants' mental models, System Dynamics Review vol 29, No 4 (October-December 2013): 216-236.

Scott, Rodney J., Robert Y. Cavana, Donald Cameron, 2014, Client perceptions of reported outcomes of group model building in the New Zealand public sector, 32nd International Conference of the System Dynamics Society, Delft, Netherlands -- July 20-24, 2014.

Scott, Rodney J., Robert Y. Cavana, Donald Cameron, 2014, Mechanisms for Understanding Mental Model Change in Group Model Building, Systems Research and Behavioral Science, (2014).

Senge, P., 1990. The Fifth Discipline: The Art and Practice of the Learning Organization. New York: Doubleday.

Siemer, William with Peter Otto, 2005, A Group Model-Building Intervention to Support Wildlife Management Decisions, The 23rd International Conference of the System Dynamics Society, July 17-21, 2005 Boston.

Smagt, Ton van der, 2006, Causation and Constitution in System Dynamics: Modelling a Socially Constituted World, Systems Research and Behavioral Science, 23, 513-524 (2006).

Stave, Krystyna A., 2002, Using system dynamics to improve public participation in environmental decisions, System Dynamics Review Vol. 18, No. 2, (Summer 2002): 139167.

Stave, Krystyna with Michael Dwyer, 2005, Modeling the Relationship between Population and Land Development under Changing Land Use Policies, The 23rd International Conference of the System Dynamics Society, July 17-21, 2005 Boston.

Sterman, J., 2000. Business Dynamics. Systems Thinking and Modeling for a Complex World. McGraw-Hill Higher Education, New York.

Stijn, Hoppenbrouwers, Etiënne Rouwette, 2011, A Dialogue Game for Group Model Building, The 29th International Conference of the System Dynamics Society, July 25 - 29, 2011, Washington, DC.

Thanh Van Mai Bosch O.J.H, and Maani E.Kambiz, 2011, Towards a shared systems model of stakeholders in tourism development in the Cat Ba biosphere reserve of Vietnam, The 29th International Conference of the System Dynamics Society, July 25 - 29, 2011, Washington, DC. 
Timothy, Bolt, Steffen Bayer, Maria Kapsali and Sally Brailsford, 2011, Object use as a framework to study model use in group model building, The 29th International Conference of the System Dynamics Society, July 25 - 29, 2011, Washington, DC.

Tsuey-Ping, Lee, Aldo Zagonel, David F. Andersen, John W. Rohrbaugh, George P. Richardson, 1998, A Judgment Approach to Estimating Parameter in Group Model-Building : A Case Study of Social Welfare Reform at Dutchess County, The 16th International Conference of The System Dynamics Society, July 20 - 23, 1998, Québec Hilton, Québec City, CANADA.

Van Gulijk, Rian with Willem Stapel, 2014, System Dynamics and GMB in Practice - the Case of Heavy Cannabis in The Netherlands, 32nd International Conference of the System Dynamics Society, Delft, Netherlands -- July 20-24, 2014.

Vennix, J.A.M., 1996, Group Model Building: Facilitating Team Learning Using System Dynamics, John Wiley \& Sons, Chichester, 1996.

Vennix, J.A.M., Gubbels, J.W., Post, D., Poppen, H.J., 1990. "A structured approach to knowledge elicitation in conceptual model building." System Dynamics Review 6 (2), 194-208.

Vennix, Jac A. M. with Jan Gubbels, Luc D. Verburghand Doeke, 1990, Post Eliciting Group Knowledge in a Computer-Based Learning Environment, The 8th International Conference of the System Dynamics Society, 1990 Chestnut Hill, Massachusetts USA.

Vennix, Jac A. M. with Jan W. Gubbels, Doeke Post and Henk J. Poppen, 1988, A Structured Approach to Knowledge Acquisition In Model Development, The 6th International Conference of the System Dynamics Society, 1988 La Jolla, CA USA.

Vennix, Jac A. M. with Wim Scheper, 1993, Group Model-building: what does the client think of it?, The 11th International Conference of the System Dynamics Society, 1993 Cancun, Mexico.

Vennix, Jac A. M., 1994, Building Consensus in Strategic Decision-Making: Insights from the process Group Model-Building, The 12th International Conference of the System Dynamics Society, 1994 Stirling, Scotland.

Vennix, Jac A. M., 1999, Group model-building: tackling messy problems, System Dynamics Review, Vol. 15, No. 4, (Winter 1999): 379-401.

Vennix, Jac A. M., Henk A. Akkermans, and Etienne A. J. A. Rouwette, 1996, Group modelbuilding to facilitate organizational change: an exploratory study, System Dynamics Review, Vol. 12, no. 1, (Spring 1996): 39-58.

Vennix, Jac A.M. with Cecile M. Thijssen and Etienne A.J.A. Rouwette, 1997, Group Model Building: A Decision Room Approach, The 15th International Conference of the System Dynamics Society, August 19-22, 1997 --- Istanbul, Turkey.

Vennix, Jac A.M., David F. Andersen, George P. Richardson, 1997, Foreword: Group model building, art, and science, System Dynamics Review, Vol. 13, No. 2, (Summer 1997): 103106.

Vennix, Jac, Huz, Steven with David F. Andersen, George P. Richardson and Roger Boothroyd, 1996, Evaluating Group Model Building in Mental Health Vocational Services, The 14th International Conference of the System Dynamics Society, 1996 Cambridge, Massachusetts, USA. 
Visser, Max, 2006, The System Dynamics of Group Facilitation and Communication, The 24th International Conference of the System Dynamics Society, July 23-27, 2006 Nijmegen, The Netherlands.

Visser, Max, 2007, System dynamics and group facilitation: contributions from communication theory, System Dynamics Review Vol. 23, No. 4, (Winter 2007): 453-463.

Voinov, A., Bousquet, F., 2010. Modelling with stakeholders. Environ. Model. Softw. 25 (11), $1268 \mathrm{e} 1281$.

Vugteveen, Pim, et al. 2015. "Developing social-ecological system indicators using group model building." Ocean \& Coastal Management 109(0): 29-39.

Wagle, Paroma, 2014, Increasing Accessibility of Participatory System Dynamics Modeling Methods: Proposal for a New Rapid Protocol, 32nd International Conference of the System Dynamics Society, Delft, Netherlands -- July 20-24, 2014.

Winz, Ines, Brierley, Gary, 2007, Participatory Methods in Environmental System Dynamics Projects, The 2007 International Conference of the System Dynamics Society and 50th Anniversay Celebration, July 29 - August 2, 2007, Boston, Massachusetts, USA.

Xiao, Bambry, Masha Serdyukova, 2013, If the hillock does not survive, the community does not survive: Insights from the SD Winter Institute in Andhra Pradesh, The 31st International Conference of the System Dynamics Society, July 21 - July 25, 2013 Cambridge, Massachusetts USA

Yadama, Gautam N., Peter S. Hovmand, Foundation for Ecological Security (Papagni Cell) and Nishesh Chalise, 2010, Community Driven Modeling of Social-Ecological Systems: Lessons from Andhra Pradesh, India, The 28th International Conference of the System Dynamics Society, July 25 - 29, 2010, Seoul, Korea.

Yahril, Shanty with Muhammad Tasrif, A. Taufik Mukhith and Lucentezza Napitupulu, 2006, Group Model Building Intervention in Developing Country: Lesson Learned from Developing Strategies for Clean Air, The 24th International Conference of the System Dynamics Society, July 23-27, 2006 Nijmegen, The Netherlands.

Yuliani, Dewi with Muhammad Tasrif, 2006, Understanding Community Empowerment Process : A Case Study of a Rural Locality in Indonesia, The 24th International Conference of the System Dynamics Society, July 23-27, 2006 Nijmegen, The Netherlands.

Zagonel, A.A. 2002. Model conceptualization in group model building: A review of the literature exploring the tension between representing reality and negotiating a social order. In Proceedings of the 2002 international conference of the system dynamics society. Albany: System Dynamics Society.

Zagonel, Aldo A., 2002, Model conceptualization in Group Model Building: A review of the literature exploring the tension between representing reality and negotiating a social order, 20th International Conference of The System Dynamics Society, July 28 - August 1, 2002, Grand Hotel Villa Igiea, Palermo, Italy.

Zagonel, Aldo A., 2004, DEVELOPING AN INTERPRETIVE DIALOGUE FOR GROUP MODEL BUILDING, The 22th International Conference of The System Dynamics Society, July 25 - 29, 2004 --- Keble College, Oxford, England.

Zagonel, Aldo with John Rohrbaugh, David F. Anderson, George Richardson and Tsuey Ping Lee, 1997, Group Model Building to Support Welfare Reform in Cortland County, The 
15th International Conference of the System Dynamics Society, August 19-22, 1997 --Istanbul, Turkey.

Zimmermann, Nici, Laura Black, Clive Shrubsole, Mike Davies, 2015, Meaning-making in the process of participatory system dynamics research, 33rd International Conference of the System Dynamics Society, Cambridge, Massachusetts, USA, July 19-23, 2015. 